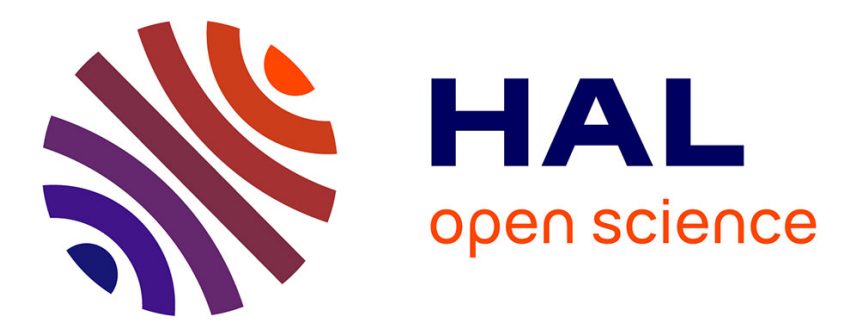

\title{
Temperature dependence of mechanical properties and pressure sensitivity in metallic glasses below glass transition
}

Vincent Keryvin, Prasad Eswar Korimilli, Yann Gueguen, Jean-Christophe Sangleboeuf, Upasdarta Ramamurty

\section{To cite this version:}

Vincent Keryvin, Prasad Eswar Korimilli, Yann Gueguen, Jean-Christophe Sangleboeuf, Upasdarta Ramamurty. Temperature dependence of mechanical properties and pressure sensitivity in metallic glasses below glass transition. Philosophical Magazine, 2008, 88 (12), pp.1773-1790. 10.1080/14786430802286971. hal-00513927

\section{HAL Id: hal-00513927 \\ https://hal.science/hal-00513927}

Submitted on 1 Sep 2010

HAL is a multi-disciplinary open access archive for the deposit and dissemination of scientific research documents, whether they are published or not. The documents may come from teaching and research institutions in France or abroad, or from public or private research centers.
L'archive ouverte pluridisciplinaire HAL, est destinée au dépôt et à la diffusion de documents scientifiques de niveau recherche, publiés ou non, émanant des établissements d'enseignement et de recherche français ou étrangers, des laboratoires publics ou privés. 


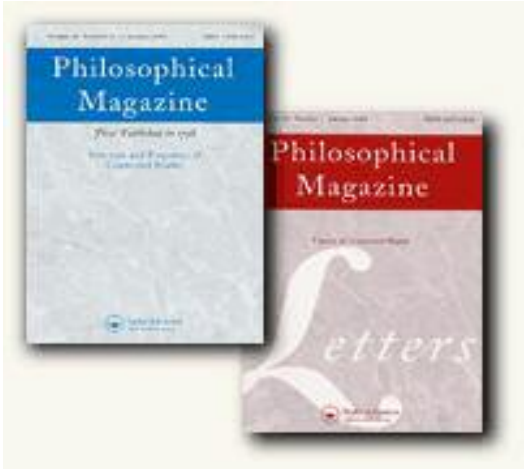

Temperature dependence of mechanical properties and pressure sensitivity in metallic glasses below glass transition

\begin{tabular}{|r|l|}
\hline Journal: & Philosophical Magazine \& Philosophical Magazine Letters \\
\hline Mournal Selection: & Philosophical Magazine \\
\hline Author: & O6-Jun-2008 \\
\hline Complete List of Authors: & $\begin{array}{l}\text { Keryvin, Vincent; LARMAUR, Universite de Rennes1 } \\
\text { Korimilli, Prasad; Indian Institute of Science, Department of } \\
\text { Materials Engineering } \\
\text { Gueguen, Yann; Universite de Rennes 1, LARMAUR } \\
\text { Sangleboeuf, Jean-Christophe } \\
\text { Ramamurty, Upasdarta; Indian Institute of Science, Materials } \\
\text { Engineering }\end{array}$ \\
\hline Keywords: & $\begin{array}{l}\text { amorphous alloys, compression, FEM, finite-element modelling, } \\
\text { hardness, indentation, mechanical behaviour, metallic glasses }\end{array}$ \\
\hline Keywords (user supplied): & constraint factor, pressure sensitivity, temperature dependence \\
\hline
\end{tabular}

\section{S) ScholaronE" \\ Manuscript Central}


Philosophical Magazine

Vol. 00, No. 00, 00 Month 200x, 1-27

\title{
RESEARCH ARTICLE
}

\section{Temperature dependence of mechanical properties and pressure sensitivity in metallic glasses below glass transition}

\author{
V. Keryvin ${ }^{\mathrm{a}, \mathrm{b} *}$, K. Eswar Prasad ${ }^{\mathrm{b}}$, Y. Gueguen ${ }^{\mathrm{a}}$, J.-C. Sanglebœuf ${ }^{\mathrm{a}}$ and U. Ramamurty ${ }^{\mathrm{b}}$ \\ ${ }^{\mathrm{a}}$ LARMAUR, Université de Rennes 1, Campus de Beaulieu, 35042 Rennes, France; ${ }^{\mathrm{b}}$ Department \\ of Materials Engineering, Indian Institute of Science, Bangalore 560 012, India \\ (Received 00 Month 200x; final version received 00 Month 200x)
}

\begin{abstract}
An experimental investigation into the variation of the mechanical properties (yield stress, yield strain, elastic moduli, hardness) from sub-ambient temperature $(77 \mathrm{~K})$ to that just below the glass transition temperature, of different bulk metallic glasses was conducted. Particular emphasis was on the constraint factor, the ratio of hardness to compressive yield stress, which is taken to be the proxy for the temperature dependency of pressure sensitive plastic flow. All the mechanical properties, except the constraint factor, decrease linearly, throughout the temperature range examined, with temperature and when normalized exhibit certain universal tendencies. The constraint factor was found to increase, monotonically but not necessarily linearly, with temperature. Finite element analyses, with pressure dependent constitutive behaviour, were performed in order to extract pressure sensitivity from the indentation load-displacement curves reported by Schuh et al. [Acta Mater. 52, 5879 (2004)]. This, in turn, was used to predict the variation of constraint factor with temperature. A good correlation suggests that the increase in constraint factor with temperature indeed is associated with enhanced pressure sensitivity.
\end{abstract}

\section{Introduction}

The fundamental mechanisms of plasticity in amorphous alloys are distinctly different from those in crystalline metals [1-3]. Whereas dislocations and their mobility mediates plasticity in the latter, shear transformation zones (STZs), collective rearrangement of clusters of atoms to accommodate shear strain, constitute unit deformation processes in all amorphous materials including metallic glasses. These microscopic differences also map to significantly diverse macroscopic behaviour. For example, unit glide of a dislocation (from one equilibrium lattice position to another) does not require any significant local dilatation (especially in those metals which have large core widths such as fcc metals) and hence continuum plasticity theories of metals invoke only the deviatoric stress. In contrast, the STZs require significant local dilatation, either transiently or permanently, for the shear transformation to take place. As a result, they are sensitive to free volume available in the material (taking place preferably in locations where free volume is high). Some manifestations of the requirement of large local dilation are high yield strains ( $\sim 2 \%$ in amorphous alloys as against typical $0.5 \%$ in crystalline metals) and more importantly sensitivity of plastic flow to the dilatational components of the stress tensor. The latter,

*Corresponding author. Email: vincent.keryvin@univ-rennes1.fr 
albeit modest when compared to that observed in amorphous polymers, has important consequences. These include tension/compression asymmetry, high hardness values, enhanced crack tip blunting [3-9], etc.

The temperature of testing (relative to the glass transition temperature $T_{g}$ ) plays an important role in determining the mechanical response of metallic glasses. In the super-cooled liquid regime (i.e. temperatures above $T_{g}$ but below the crystallization temperature), STZs operate everywhere and flow is homogeneous. In contrast, below $T_{g}$, which is of interest in this study, STZs tend to link up along the planes of maximum shear stress and plastic flow localizes into narrow bands, often referred to as 'shear bands'. While room temperature and above $T_{g}$ properties of metallic glasses are extensively investigated, the intermediate temperature properties are not studied in a comprehensive manner. In particular, "how do mechanical properties of amorphous alloys vary as a function of temperature below the $T_{g}$ ?" is a question that we seek to address in this paper. We note that Lu et al. [10] have examined in detail the strain rate and temperature dependence of the Zr-based bulk metallic glass (BMG), Vitreloy-1. Johnson and Samwer [11] propose, primarily on the basis of Lu et al.'s data, a universal yield strain in BMGs with a power-law temperature dependence. We shall return to these later.

The emphasis of this paper is on the temperature dependence of pressure sensitivity in BMGs. For this purpose, we employ indentation, which has been successfully employed to investigate the deformation mechanisms and pressure sensitivity in these materials $[4,7,8,12-20]$. In addition to indentation, we studied the uniaxial compressive properties of BMGs as a function of temperature, as they are necessary to evaluate constraint factor and understand possible origins of its variation with temperature. These experimental results are coupled with finite element analyses (FEA) to confirm that pressure sensitivity indeed increases with temperature as suggested by the constraint factor.

\section{Materials and experiments}

We have investigated two different BMGs in this work. Their nominal compositions (in at.\%) are $\mathrm{Zr}_{55} \mathrm{Cu}_{30} \mathrm{Al}_{10} \mathrm{Ni}_{5}$ (referred to as $\mathrm{ZrCuAlNi}$ here afterwards) and $\mathrm{Pd}_{40} \mathrm{Ni}_{40} \mathrm{P}_{20}$ (referred to as PdNiP). Details about processing of these alloys can be found in [21]. In addition to these two alloys, we also use the yield stress [10] and the hardness data [22] of another BMG, $\mathrm{Zr}_{41.2} \mathrm{Ti}_{13.75} \mathrm{Cu}_{12.5} \mathrm{Ni}_{10} \mathrm{Be}_{22.5}$ (referred to as Vit-1), in this paper. The $T_{g}$ of the three alloys are listed in Table 1.

Uniaxial compression tests were performed on cylindrical specimens with a nominal length-to-diameter ratio of 3:2 (diameter of 4.38-4.62 mm for PdNiP and $2.9 \mathrm{~mm}$ for Zr$\mathrm{CuAlNi}$. These cylinders were cut with a diamond-precision saw and mounted in a steel block before being ground using a plane grinding machine. Final grinding was performed using $\mathrm{SiC}$ grinding papers up to \#4000 using the same block to preserve parallelism and flatness.

Compression tests were conducted in a screw-driven universal testing machine under displacement-control with anvils made from WC-Co rods (6 mm dia.). The anvils were guided through a specially designed cylindrical steel block to ensure a perfect align- 
ment of the load. Friction between the compression anvils and specimens was minimised via the use of $\mathrm{MoS}_{2}$ lubricant. All the tests were performed at a nominal strain rate of $1.5 \times 10^{-5} \mathrm{~s}^{-1}$ except for the tests at $77 \mathrm{~K}$ which were performed at $3.3 \times 10^{-4} \mathrm{~s}^{-1}$. (The higher rate at $77 \mathrm{~K}$ was necessary in order to optimize the testing time. Given that the BMGs are strain rate insensitive [10], especially at such low temperatures, we believe that this change in rate has no significant bearing on the results discussed later.)

For high temperature testing, the samples were heated in air. Temperature control is assigned by a K-thermocouple placed $\sim 1 \mathrm{~mm}$ close to the specimen through a window made in the steel block. The high temperature testing sequence consisted of heating the specimen to the target temperature in $\sim 30 \mathrm{~min}$, a $15 \mathrm{~min}$ soak, application of load until failure (which took up to $\sim 1 \mathrm{~h}$ ), gentle cooling to room temperature (RT, $293 \mathrm{~K}$ ). Experiments at low temperature $(77 \mathrm{~K})$ were conducted with the sample placed in a liquid nitrogen tank with two walls separating the specimen and the liquid. Vacuum was made in between the two walls and a polymeric foam was placed at the top of the tank for insulation. Loading commenced once the level of liquid nitrogen stabilised. The same guiding device, employed at elevated temperatures, was used for the compression tests.

In addition to RT, compression tests were conducted at 77, 373, 423 and $473 \mathrm{~K}$ for the $\mathrm{PdNiP}$ and at 77, 473 and $573 \mathrm{~K}$ for the $\mathrm{ZrCuAlNi}$. The temperatures were controlled to within $1 \mathrm{~K}$ of the desired temperature. Three specimens were tested for each temperature. The true compressive yield stress, $\mathrm{Y}_{c}$, was computed by taking the ratio of the maximum load at failure to the cross section area. This latter value was taken as the initial cross section corrected (assuming incompressibility) by the yield strains, which were calculated for each glass by using their Young's modulus values at each temperature [23, 24].

Indentation experiments were conducted on $5 \mathrm{~mm}$ thick disks cut from the rods using diamond precision saw and polished up to a mirror finish using $\mathrm{SiC}$ papers and $1 \mu \mathrm{m}$ diamond paste. Indentation at RT and high temperatures was performed with an in-house designed micro-indentation apparatus [25] with a Vickers diamond indenter. The samples were heated in a Pyrox Mn20/100 furnace with an assigned temperature loading. Both the sample and the indenter were placed in an alumina tube, the latter being in the furnace. A K-thermocouple was placed near the sample to closely monitor the temperature. The temperature control consisted in reaching the target temperature (at about the same rate used for compression samples), performing ten indentations in sequence (by turning an alumina screw at the end of the alumina tube), and gentle cooling. A maximum load, $P_{\text {max }}$, of $5 \mathrm{~N}$, a loading rate of $0.083 \mathrm{~N} / \mathrm{s}$ and a dwell time of $30 \mathrm{~s}$ were employed. In all, the specimen was at the testing temperature for about an hour. Indentation experiments at $77 \mathrm{~K}$ were performed using the same apparatus as that for uniaxial compression testing. Optical microscopy (Olympus BX60F-3) was used to measure the lengths of the diagonals, $2 a$, of the square indentation. Ten indentations were made for each temperature. Then, the mean contact pressure or Meyer's hardness, $H$, was computed as $P_{\text {max }}$ divided by the projected area of contact so that $H=P_{\max } / 2 a^{2}$. Hardness was measured at 77, 293, 373, 423 and $473 \mathrm{~K}$ for PdNiP and 77, 293, 373, 473 and $573 \mathrm{~K}$ for ZrCuAlNi. 


\section{Temperature dependence of mechanical properties}

\subsection{Variation of uniaxial properties with temperature}

True yield stress $Y_{c}$ data resulting from the compression tests on the three alloys in the temperature range of 77 to $573 \mathrm{~K}$ are presented in Figure ??. Note that barrelling will always occur, despite the use of lubricant, which only reduces the friction at the ends of the compression. A consequence of barrelling is that the experimentally measured values of $Y_{c}$ will always be lower than the actual values of $Y_{c}$. Therefore, in Figure 1, as well as subsequent calculations, the maximum value of $Y_{c}$ obtained, among the three tested specimens for each case, at a given temperature, is taken. For comparison, at RT, a nominal yield stress of $1.73 \mathrm{GPa}$ was found on PdNiP that is very close to the values of "above $1.7 \mathrm{GPa}$ " [5] or $1.78 \mathrm{GPa}$ [4] reported in literature for this alloy. For the $\mathrm{ZrCuAlNi}$, we obtained a nominal value of $1.7 \mathrm{GPa}$, which is comparable with the literature values [26]. Note that the data for Vit-1 were obtained at a strain rate of $10^{-4} \mathrm{~s}-1$, which is similar to that used in the present study.

Figure ?? suggests that $Y_{c}$ decreases linearly with temperature for all the three alloys. At a given temperature, Vit-1 is $\sim 400 \mathrm{MPa}$ stronger vis-à-vis the other two BMGs. Interestingly, the slopes $\left(\mathrm{d} Y_{c} / \mathrm{d} T\right)$ for both the Zr-based BMGs are similar (11.8 and $\left.13.4 \mathrm{MPa} / \mathrm{K}\right)$ whereas that of the PdNiP is significantly larger at $17.4 \mathrm{MPa} / \mathrm{K}$. These data are listed in Table 2.

It is instructive to compare the three alloys on a normalised basis. The $T_{g}$ is a natural normalising parameter for the testing temperature. Strictly speaking $T / T_{m}$ (where $T_{m}$ is melting temperature) is homologous temperature. However, for glasses, $T_{g}$ is a more relevant temperature. For the mechanical properties, normalising with RT values is not necessarily correct as RT correspond to different levels of $T / T_{g}$, since $T_{g}$ is different for different alloys. Therefore, we chose the value at $0.5 T_{g}$ as the reference value. Note that in many cases we did not measure the property at that specific temperature. In such cases, we have taken the interpolated value as the basis.

Normalised compressive yield stresses were plotted as a function of $T / T_{g}$. It is seen that all the data collapse on to a single curve. We employed both linear and power-law fits to see which of these two describes the trends better. While both the fits are excellent (with regression coefficients close to 0.98 or better), the power-law is slightly better. However, the difference is marginal for us to conclude as to which law best describes the variation of $Y_{c}$ with $T$.

Before proceeding to the yield strain, we examine the variation in elastic moduli with temperature. Our experimental configuration does not allow us to measure strains by mounting of a strain gauge or an extensometer. Therefore, we resort to the literature where there is a wealth of data on the temperature dependence of elastic properties of BMGs. Figure 2 shows the variations of Young's modulus $E$ and shear modulus $G$ with temperature. Data are taken from our earlier work [23, 27] for the $\mathrm{ZrCuAlNi}$ or from literature [24] for PdNiP. Linear regression results are indicated in Figure 2 and the slopes are listed in Table 2. The variations of elastic moduli from RT to temperatures just below $T_{g}$ have been extrapolated to $77 \mathrm{~K}$. This assumption is consistent with recent results of temperature de- 
pendence of elastic moduli on a variety of BMGs by Zhang et al. [28]. Indeed, they have shown that deviation from linearity only occurs at very low temperatures, below $77 \mathrm{~K}$. For Vit-1, similar data were not available. Therefore, temperature dependence of $E$ was deduced from the one of the shear modulus [11], assuming a constant Poisson's ratio of 0.357 , which is good approximation below $T_{g}$ [28].

True compressive yield strains, $\epsilon_{y}$, calculated from the $Y_{c}$ and $E$ data, are plotted in Figure 3. Again, the temperature dependence appears to be linear. In contrast to $Y_{c}$, the $\epsilon_{y}$ variations with temperature in the two Zr-based alloys are remarkably similar whereas $\epsilon_{y}$ values for the PdNiP are lower (by about $0.5 \%$ at a given temperature) than those of the Zr-based alloys. Further, the slope for the PdNiP is larger than that seen in Zr BMGs. A normalised plot for the three amorphous alloys is made in Figure 3, using the same procedure adopted in Fig. 1. Like in Fig. 1, a general linear trend is evident.

\subsection{Hardness and constraint factor}

Variations in $H$ with temperature are shown in Figure ??. Note that the Vickers hardness data of Vit-1 obtained by Eswar Prasad et al. [22] were converted into Meyer's hardness before plotting in this figure. The hardness trends are, yet again, broadly linear, with the Vit-1 being the hardest and $\mathrm{ZrCuAlNi}$ being softest among the three. (Recall that the $Y_{c}$ data, on the other hand, indicates that PdNiP and $\mathrm{ZrCuAlNi}$ have similar yield stresses.) However, when the temperature and hardness are normalised appropriately (see Figure ??), a single linear curve is able to successfully describe the trend in all the three glasses. These results show no drastic softening up to $\sim 0.85 T_{g}$, which is consistent with earlier work from Le Bourhis and Rouxel [29] on the same ZrCuAlNi BMG, while Wesseling et al. [30] reported significant softening beyond $\sim 0.7-0.8 T_{g}$ in a Cu-based BMG. The relatively small discrepancy in these works may be due to prior annealings around crystallisation temperature for the former study [29].

The constraint factor, $C$, that is the ratio mean contact pressure, $H$, to compressive yield stress, $Y_{c}$, is computed and plotted as function of the homologous temperature, $T / T_{g}$, in Figure 5. While there is a monotonic increase in $C$ with $T / T_{g}$, a clear functional relation is not evident, with PdNiP data being much higher than the rest two BMGs for $T>0.7 T_{g}$. Starting at $\sim 2.9$ at $77 \mathrm{~K}, C$ reaches values as high as 3.55 to 3.75 above $0.7 T_{g}$. If only the $\mathrm{Zr}$-based BMGs are considered, whose values are remarkably similar throughout the temperature range examined, it appears that the $C$ reaches a plateau value (between 3.5 and 3.6) above $T / T_{g} \sim 0.7$.

Patnaik et al. [7] and later Keryvin [8] have shown that a high $C$ value in BMGs is a result of the pressure sensitivity to plastic flow in them. Then, results presented in Fig. 5 suggest that as the temperature increases so does the pressure sensitivity, which in contrast with all the other mechanical properties which decrease with temperature. In following, we examine other possible evidence for this. 


\section{Temperature dependence of pressure sensitivity in $\mathbf{P d}_{40} \mathbf{N i}_{40} \mathbf{P}_{20}$}

Instrumented indentation methods refer to hardness tests wherein load, $P$, vs. depth of penetration, $h$, curves are continuously monitored during loading as well as unloading. A wealth of information can be obtained from these tests, especially on small volume materials such as thin films, and hence these techniques have become popular for probing mechanical properties in recent years. In the metallic glasses context, the $P$ - $h$ curves have been successfully utilised to understand shear banding events, strain rate sensitivity, temperature-dependence of flow characteristics [13-16]. Vaidyanathan et al. [20] have conducted FEA of the $P$ - $h$ curves obtained on Vit-1 through RT nanoindentation and showed that the pressure-insensitive von Mises yield criterion can not capture the experimental trends accurately. The Mohr-Coulomb (MC) criterion, which takes the normal stress acting on the shear plane also into account, was necessary for the correct replication of experiments through simulation. This was also later shown by Patnaik et al. [7] and Keryvin [8], who examined the connections between hardness and pressure sensitivity and showed that the hydrostatic compressive stresses underneath the indenter lead to high hardness values in MGs. Motivated by this, we employ numerical modelling to extract the friction angle (an indicator of pressure sensitivity) from the experimental $P-h$ curves reported by Schuh et al. [15] at various temperatures on PdNiP. Our objective in conducting this exercise is to see if the friction angle also increases with temperature, which would corroborate the pressure sensitivity increase with temperature suggested by C.

\subsection{Numerical procedures}

Axisymmetric indentation FEA were performed using Cast3M software [31] developed by the French Atomic Energy Agency. A planar mesh consisting of 2,073 four-noded quadrilateral elements, with coarse meshing far from the indentation zone and a finer meshing beneath the indentation zone, was employed. At least 30 elements were in contact with the indenter at maximum load (each contact element is $5.8 \mathrm{~nm}$ in length). The size of the mesh was chosen such that it is insensitive to the far-field boundary conditions. All simulations were performed under displacement control and finite deformation formulation was used. Indentation was performed with a diamond conical indenter $(E=$ $1,100 \mathrm{GPa}, \nu=0.07$ ) with a half-apex angle of $70.3^{\circ}$, which is equivalent to the Vickers or Berkovich pyramidal indenters [32]. The indenter tip was made spherical, with the tip radius, $R$, as one of the variable, so as to account both for imperfect initial machining and for possible blunting during extended use. The contact between the indenter and the BMG is taken to be frictionless, especially since friction plays a very limited role on the $P$ - $h$ curves during indentation with high apex angle cones [32]. An associative elasticperfectly plastic Drucker-Prager (DP) behaviour was used for BMG's flow response. 


\subsection{Estimation of the friction angle from nanoindentation experiments}

Recently, Schuh et al. [15] conducted nanoindentation experiments on PdNiP at temperatures ranging from RT to $473 \mathrm{~K}$ (see Figure 6). The experimental $P$ - $h$ curves (only the loading portions) reported by them are shown in Fig. 6. FEA was performed to match the experimental $P$ - $h$ curves simulated ones with varying friction parameter. For RT simulations, we took the elastic parameters from the work of Ichitsubo et al. [24] (see Figure 2), as well as the compressive yield stresses $Y_{c}$ from the present work. The tensile yield stress $Y_{t}$ is taken from the work of Mukai et al. [6] and $R$ is the fitting parameter. For other temperatures, $Y_{t}$ is the only unknown and some trial values are used to fit the experimental data. All values $\left(E, \nu, Y_{c}, Y_{t}\right)$ are reported in Table 3 . The asymmetry in tensile vs. compressive yield stress data gives the value of the friction angle ${ }^{1}, \alpha$, used in the DP yield criterion that can be expressed as follows:

$$
\sigma_{e q}+\sigma_{m} \tan \alpha-\left(1-\frac{1}{3} \tan \alpha\right) Y_{c} \leq 0 \quad ; \quad \alpha=\arctan 3 \frac{Y_{c}-Y_{t}}{Y_{c}+Y_{t}}
$$

where $\sigma_{m}=\frac{1}{3} \operatorname{tr} \underset{\sim}{\sigma}$ is the mean stress ( $\underset{\sim}{\sigma}$ is the Cauchy stress tensor) and $\sigma_{e q}=\sqrt{3} \sqrt{J_{2}^{s}}=$ $\sqrt{\frac{3}{2} s: s}$ is the equivalent shear stress in tension ( $s$ is the deviatoric stress tensor).

We note that the aim of this comparison, experimental data vs. numerical simulations, is not to specifically extract exact values of $\alpha$ but evaluate the change in its relative value with temperature. Figure 6 shows simulated and experimental $P$ - $h$ curves. In essence, there are only two 'fitting' parameters in the simulations: $R$ and $\alpha$. At RT, available experimental tensile and compressive yield stresses give an $\alpha=7.65^{\circ}$. Therefore, for RT, we vary only $R$ and find that the simulated $P$ - $h$ curve matches well with the experiment when $R=400 \mathrm{~nm}$, which is reasonable from a practical stand point of view. Subsequent simulations of high temperature $P$ - $h$ curves were performed with $R$ fixed at $400 \mathrm{~nm}$ and only $\alpha$ as the variable parameter.

Figure 6 shows that, as the temperature increases, the $\alpha$ value of the simulation has to be increased, necessarily, so as to match with experiments. For example, $\alpha$ has to be increased to $15^{\circ}$ for describing the experimental $P$ - $h$ curve at $373 \mathrm{~K}$ as the predicted curve with $\alpha=7.65^{\circ}$ fails to match well. Thus, approximate $\alpha$ values of 7.65, 10, 15, and $22^{\circ}$ are extracted from the RT, 323, 373, and $423 \mathrm{~K}$ experiments. We could not fit the $473 \mathrm{~K}$ curve reasonably with any of our simulations. Even when we assumed a pressure insensitive behaviour, i.e. von Mises (limit of DP using a null value of $\alpha$ ), a reasonable fit could not be achieved. We surmise that the data at this high temperature is either not reliable or completely different mechanisms (such as creep) may have become operational; the latter possibility was suggested by Schuh et al. [15].

It must be stated that we used an associative flow rule in our simulations, which explicitly implies that the dilatancy angle is equal to $\alpha$ [12]. Taking a non-associative flow rule with a dilatancy angle between $0^{\circ}$ (pure shear flow) and $\alpha$ would result in a lower contact stiffness (i.e. relatively compliant $P$ - $h$ curve), requiring further higher values of $\alpha$ for matching with the experiments.

\footnotetext{
${ }^{1}$ This denomination of 'friction angle' should be reserved, in principle, to the Mohr-Coulomb model.
} 


\subsection{Estimation of the constraint factor}

Variation of the extracted $\alpha$ with the temperature are plotted in Figure 8. Approximately linear variation, with a slope of $0.11^{\circ} / \mathrm{K}$, is seen. We now use these $\alpha$ values to estimate the $C$ variation with temperature. This was done with the aid of the modified expanding cavity model (MECM) proposed by Narasimhan [33], which takes the pressure sensitivity into account. Patnaik et al. [7] and Keryvin [8] have shown that MECM captures the experimental trends in normalised indentation stress (ratio of $H$ to $Y_{c}$ ) vs. normalised indentation strain in the elasto-plastic regime of BMGs at room temperature well.

Variation of $H / Y_{c}$ with indentation strain for various values of $\alpha$ is plotted in Figure 7. Here, the normalised indentation strain is the ratio of the indentation strain, $\epsilon_{i}$, proposed by Johnson [34] to yield strain, $\epsilon_{y}$, of the material. Values of $C$ at various temperatures were extracted from these plots at $\epsilon_{i} / \epsilon_{y}=35$, which corresponds to the onset of fully plastic regime during indentation $[8,34,35]$. Recall that the experiments were conducted using a Vickers indenter. Keryvin [8] has shown that this geometry is sharp enough for the PdNiP to enter into fully plastic regime whereas it may not be so for other BMGs.

Values of $C$ estimated using the MECM model are listed in Table 3 and plotted in Fig. 8 along with the experimental $C$ values. Reasonably good agreement between experimental and estimated values of $C$ confirms the inference of the enhancement of pressure sensitivity with temperature from $C$ measurements.

\section{Discussion}

\subsection{Variation of shear yield strains}

Results presented in this paper thus far suggest that all the mechanical properties decrease linearly with temperature. Note that the fact $Y_{c}$ and $E$ decrease linearly does not necessarily mean that $\epsilon_{y}$ also has to decrease linearly, but the experimental data suggest that it does. In this context, it is worth noting that Johnson and Samwer [11] suggested a powerlaw functional relation between the shear yield strain, $\gamma_{y}$, and $T / T g$ and offer theoretical rationalisation in terms of scaling behaviour expected for a fold catastrophe of a critical shear event. Plotting data for a wide variety of metallic glasses, they arrived at a power law exponent of $2 / 3$. Most importantly, they postulated a universal criterion for plastic yielding (UCPY) that states that shear yield strain for all metallic glass systems is $3.6 \pm 0.2 \%$ at $0 \mathrm{~K}$, which was obtained by fitting the power law to the experimental data obtained on a variety of amorphous alloys with different $T_{g}$ and the Vit- 1 alloy at different temperatures. We critically examined this aspect with our experimental results. First, we converted the $Y_{c}$ data (Fig. ??) to shear yield stresses, $\tau_{y}$, assuming Tresca yield criterion (i.e. multiplied $Y_{c}$ by a factor of 0.5 ). These are then converted into $\gamma_{y}$ with the knowledge of temperaturedependent shear modulus $G(T)$ (Fig. 2). Variation of $\gamma_{y}$ with normalised temperature is plotted in Figure 9 for the three different BMGs examined in this work. While the two $\mathrm{Zr}$ based alloys exhibit similar values of $\gamma_{y}$ at a given $T / T_{g}$, the PdNiP alloy has clearly lower $\gamma_{y}$. The $\mathrm{Zr}$ alloys data are described by power laws well, with exponents of 0.6 and 0.512 for $\mathrm{ZrCuAlNi}$ and Vit-1, respectively. These exponents, while not exactly 0.66 predicted by the UCPY, are close to it (especially given the small amount of data of our study). For 
the $\mathrm{Zr}$ alloys, $\gamma_{y}$ values at $0 \mathrm{~K}$ are 3.47 and $3.45 \%$, close to the value of $3.6 \pm 0.2 \%$ of UCPY.

The data for PdNiP alloy are in complete contrast. Power law fits with three free variables suggest that linear scaling is the best fit, with the $\gamma_{y}$ at $0 \mathrm{~K}$ equal to $2.8 \%$, which is $25 \%$ lower than that postulated by UCPY. (It appears that the seemingly good fit in Fig. 2 of Johnson and Samwer's paper is because of the relatively large range of strains covered by the y-axis.) This clearly suggests that the UCPY, which is primarily built on the basis of data obtained on Vit-1, may not be able describe all the amorphous alloys.

In any case, Fig. 9 shows that the shear flow resistance of all the BMGs decreases with temperature, which in turn suggests easier activation of STZs with increasing temperature, which is expected intuitively. One could also expect STZs occurring in larger numbers at higher temperatures. However, the consequences of the latter remain unclear. Schuh et al. [15] suggest that the STZ operation is followed by clustering of them leading to eventual nucleation and propagation of shear bands. The transitions between these different steps and more particularly the question of the formation of clusters are still open scientific issues in MGs. Actually, profuse STZ operation does not necessarily lead to shear-band nucleation but could lead to homogenization of deformation. However this scenario was not evident in compression tests or during indentation testing. In the former case, catastrophic failure always occurred at all temperatures with insignificant plastic strains. Post mortem observation of compression tested specimens also does not indicate significant plastic flow.

\subsection{Increase in pressure sensitivity with temperature}

Turning attention to $C$ variation with temperature, it is already noted that it exhibits a contrasting trend, namely increasing with temperature, indicating enhancement of pressure sensitivity with temperature. It is to be noted here that experiments at $77 \mathrm{~K}$ give $C$ $\sim 2.9$, which are similar to those observed in crystalline metals. This implies that at low temperature flow in BMGs is not or negligibly pressure sensitive and plasticity only depends on deviatoric stress $[7,8,12]$. A survey of the literature shows only one explicit study on the variation of $C$ with $T$ was conducted on crystalline alloys hitherto. In this study, Kumaraswamy and Venkataraman [35] show that $C$ in the fully-plastic regime is a constant at 2.9 for Ti-6Al-4V alloy. Therefore, the increase in $C$ with $T$ appears to be characteristic to amorphous materials like BMGs. An additional difference between other mechanical properties and $C$ is that is $C$ vs. $T$ is not linear but appears to reach a plateau for the Zr-based alloys at temperatures above $0.7 T_{g}$ whereas it continues to rise for the PdNiP alloy. The latter observation again reinforces the notion that there could be subtle and yet fundamental differences in the way different alloys respond to stress and broad generalisations on mechanical response of amorphous alloys should be made with caution.

It is instructive to examine various experimental artifacts that could possibly affect the results and significant implications of this study. The fact that compression tests inevitably lead to barrelling because of friction has already been mentioned in Section 2. The underestimation of the compressive strength may be a cause for having such high constraint 
factor values. However, the barrelling-induced strength reduction is not so substantial to fully negate the observed enhancement in $C$. The second possibility is that of BMG undergoing structural relaxation due to the long holding times (around one hour) at high temperature (but still fairly below $T_{g}$ ) and in turn affecting their flow behavior. While it is true that structural relaxation affects some mechanical properties dramatically [36], it does not affect the hardness significantly [37]. Eswar Prasad et al. [22] have examined this issue in detail and showed that this possibility is also ruled out. Thus, we can conclude, with reasonable degree of confidence, that the enhancement in $C$ with temperature is true. We seek mechanistic rationalization for it in the next section.

\subsection{Shear-band morphology}

Since plastic flow in amorphous alloys below $T_{g}$ occurs inhomogeneously, it is instructive to examine the shear band morphology. Ramamurty et al. $[38,39]$ have shown that close observation of indentation imprints and the shear band pattern around it could give important insights into the plastic flow characteristics in BMGs. Note that Vickers indentation at RT does not lead to fully-plastic regime of flow for ZrCuAlNi, so shear bands are hardly noticeable in all cases [8]. For PdNiP, the geometry of this indenter corresponds to early stages of the fully plastic regime, therefore shear-bands in high number density are not observed at RT. As yield strains decrease with temperature, $\epsilon_{i} / \epsilon_{y}$ increases, so a natural expectation would be to see a gradual increase in shear band density with temperature proviso some other micromechanism does not interfere. However, this was not the case to be, as the indentations made at different temperatures look similar (see Figure 10). This is better illustrated with the images of the indentations made with a sharper indenter $\left(90^{\circ}\right.$ cone) on PdNiP and $\mathrm{ZrCuAlNi}$, using a $50 \mathrm{~N}$ load. The use of this indenter allows for the fully plastic regime to be attained [8] and hence a large number of shear bands reach the free surface (see Figure 11). Prima facie, it does not appear that changes in the type or number of shear bands are occurring with increasing temperature.

Another possible scenario is that the propagation of shear-bands rather than their nucleation could become easier with increasing temperature. In that case each shear-band could carry more plastic deformation so that the shear-band spacing would increase [40]. However, our observations do not prove this one way or another. While there are a number of studies in the literature which are concerned with the effects of pressure sensitivity on the flow and fracture properties of BMGs [7, 8, 20, 33, 39, 41-48], Lu and Ravichandran [44]'s multiaxial experiments on Vit-1 appear particularly relevant here. In that study, they observed that the shear-bands were formed at $45^{\circ}$ vis-à-vis the loading axis, implying that shear band formation or propagation (or both) might not have anything to do with the pressure sensitivity. This combined with our observation of shear band patterns around indentation imprints changing insignificantly with temperature suggests that clues about the physical reasons for enhancement of pressure sensitivity with temperature may be not obtained from observations of shear bands morphology.

Yet another way is to examine the serrations (or 'pop-ins') in the $P$ - $h$ curves obtained during nanoindentation. Two aspects of pop-ins need to be examined; number density and width of the pop-in. While the former relates to the number of shear bands, the latter indi- 
cates the strain associated with each displacement burst. Schuh et al. [15], who conducted nanoindentation experiments on two different BMGs at different temperatures, reported increase in size and number of the serrations with increasing temperature. However, our observations presented in preceding paragraphs do not provide any convincing evidence to this effect. This leads us to conclude that while there might be subtle changes in shear band phenomenology, it is not significant enough to fully rationalize the experimental trends in plastic flow characteristics of BMGs examined in this work.

As mentioned in the introduction, STZs are raison d'être for the pressure sensitive plastic flow in amorphous alloys. It is, therefore, natural, for one to explore the STZs for possible explanation of the enhanced pressure sensitivity with temperature. However, how the size and character of STZs change with temperature has not been addressed in literature hitherto. Johnson and Samwer's model [11] suggests, albeit in an indirect way, that the critical cluster size involved in the shear transformation process should decrease with temperature as the shear yield strain decreases with temperature. It may be possible the relative role of hydrostatic yield strain on the STZs increases with temperature. Our experimental results support this hypothesis in an indirect way. Experiments conducted at $77 \mathrm{~K}$ show that $C \sim$ 2.9 at that temperature, which is typically that observed (or slightly above) for crystalline metals which do not depend on deviatoric stress. This implies that the state of hydrostatic stress is inconsequential at very low temperatures and only the shear stresses matter. As temperatures increases the pressure sensitivity increases whereas the critical shear yield strain decreases. Detailed understanding of the relative changes in these parameters needs further investigation through molecular dynamics simulations.

\section{Summary}

The mechanical properties of three bulk metallic glasses $\left(\mathrm{Zr}_{55} \mathrm{Cu}_{30} \mathrm{Al}_{10} \mathrm{Ni}_{5}, \mathrm{Pd}_{40} \mathrm{Ni}_{40} \mathrm{P}_{20}\right.$ and $\mathrm{Zr}_{41.2} \mathrm{Ti}_{13.75} \mathrm{Cu}_{12.5} \mathrm{Ni}_{10} \mathrm{Be}_{22.5}$ ) between $77 \mathrm{~K}$ and $0.9 \mathrm{~T}_{g}$ have been examined. Experimental results show that elastic moduli, yield stress and strain, and hardness all decrease linearly with temperature within the temperature range examined. Normalized plots indicate that yield stress and hardness exhibit a universal trend independent of the composition whereas yield strains do show some broad compositional dependence. In contrast to other mechanical properties, the constraint factor was found increase from $\sim 2.9$, which is representative of that in crystalline metals, to $\sim 3.7$ at $0.9 T_{g}$. Numerical analysis of the $P-h$ curves obtained on the $\mathrm{Pd}_{40} \mathrm{Ni}_{40} \mathrm{P}_{20}$ alloy by Schuh et al. [15] as a function of temperature supports the conclusion of enhancement of pressure sensitivity to plastic flow with temperature inferred from the constraint factor variation. No significant changes to shear morphologies with temperature could be noted inferring that increased pressure sensitivity with temperature could be due to enhanced sensitivity of STZ operation to the hydrostatic component of the stress tensor at higher temperatures. 


\section{Acknowledgements}

The authors thank Prof. Y. Kawamura (Kumamoto University, Japan) and Prof. Y. Yokoyama (Tohoku University, Japan) for providing respectively the Pd-based and the Zr-based samples that were examined in this work, respectively. Experimental assistance from Dr. C. Bernard, A. Burguière, H. Orain, M. Le Fur and B. Truffin (LARMAUR, University of Rennes1) is acknowledged. We thank Prof. R. Narasimhan (Indian Institute of Science) for providing us with the data of his modified expanding cavity model. VK thanks the Indian Institute of Science for a visiting Professorship during which period this work was completed. He also acknowledges partial financial support from the French Embassy in India and EGIDE mobility programme. Research work on BMGs at IISc was sponsored by the Defence Research and Development Organization (DRDO), Govt. of India.

\section{References}

[1] A.S. Argon, Plastic deformation in metallic glass, Acta Metall 27(1) (1979), pp. 47-58.

[2] F. Spaepen, A microscopic mechanism for steady state inhomogeneous flow in metallic glasses, Acta Metall 25 (1977), pp. 407-415.

[3] C.A. Schuh, T.C. Hufnagel, and U. Ramamurty, Mechanical behavior of amorphous alloys, Acta Mater 55(12) (2007), pp. 4067-4109.

[4] P. Donovan, Plastic flow and fracture of $P d_{40} N i_{40} P_{20}$ metallic glass under an indentor, J Mater Sci 24 (1989), pp. 523-535.

[5] T. Mukai et al., Effect of strain rate on compressive behavior of a $P d_{40} N i_{40} P_{20}$ bulk metallic glass, Intermetallics 10 (2002), pp. 1071-1077.

[6] T. Mukai et al., Dynamic response of a $\mathrm{Pd}_{40} N i_{40} P_{20}$ bulk metallic glass in tension, Scripta Mater 46(1) (2002), pp. 43-47.

[7] M. Patnaik, R. Narasimhan, and U. Ramamurty, Spherical indentation response of metallic glasses, Acta Mater 52(11) (2004), pp. 3335-3345.

[8] V. Keryvin, Indentation of bulk metallic glasses: Relationships between shear-bands observed around the prints and hardness, Acta Mater 55 (2007), pp. 2565-2578.

[9] P. Tandaiya, R. Narasimhan, and U. Ramamurty, Mode I crack tip fields in amoprhous materials with application to metallic glasses, Acta Mater 55 (2007), pp. 6541-6552.

[10] J. Lu, G. Ravichandran, and W.L. Johnson, Deformation behavior of the $\mathrm{Zr}_{41.2} \mathrm{Ti}_{13.8} \mathrm{Cu}_{12.5} \mathrm{Ni}_{10.0} \mathrm{Be}_{22.5} \mathrm{bulk}$ metallic glass over a wide range of strain-rates and temperatures, Acta Mater 51(12) (2003), pp. 3429-3443.

[11] W.L. Johnson and K. Samwer, A universal criterion for plastic yielding of metallic glasses with a $\left(T / T_{g}\right)^{(2 / 3)}$ temperature dependence, Phys Rev Let 95(19) (2005), p. 195501.

[12] V. Keryvin, Indentation as a probe for pressure sensitivity, J Phys: Cond Matter 20 (2008), p. 114119.

[13] Y. Golovin et al., Serrated plastic flow during nanoindentation of a bulk metallic glass, Scripta Mater 45 (2001), pp. 947-952.

[14] C.A. Schuh and T.G. Nieh, A nanoindentation study of serrated flow in bulk metallic glasses, Acta Mater 51 (2003), pp. 87-99.

[15] C.A. Schuh, A.C. Lund, and T.G. Nieh, New regime of homogeneous flow in the deformation map of metallic glasses: elevated temperature nanoindentation experiments nd mechanistic modelling, Acta Mater 52 (2004), pp. 5879-5891.

[16] C.A. Schuh and T.G. Nieh, A survey of instrumented indentation studies on metallic glasses, J Mater Res 19(1) (2004), pp. 46-57.

[17] S. Jana et al., Subsurface deformation during Vickers indentation of bulk metallic glasses, Mater Sci Eng A 375-377 (2004), pp. 1191-1195.

[18] R. Bhowmick et al., Plastic flow softening in a bulk metallic glass, Acta Mater 54 (2006), p. 4221.

[19] V. Keryvin et al., Indentation and scratching mechanisms of a ZrCuAlNi bulk metallic glass, J Phys D: Appl Phys 41 (2008), p. 074029.

[20] R. Vaidyanathan et al., Study of mechanical deformation in bulk metallic glass through instrumented indentation, Acta Mater 49 (2001), pp. 3781-3789.

[21] A. Inoue Bulk Amorphous Alloys - Practical Characteristics and Applications, Materials Science Foundations, Trans Tech Publications, 1999. 
[22] K. Eswar Prasad, R. Raghavan, and U. Ramamurty, Temperature dependence of pressure sensitivity in a metallic glass, Scripta Mater 57(2) (2007), pp. 121-124.

[23] V. Keryvin et al., Thermal stability and crystallisation of a $\mathrm{Zr}_{55} \mathrm{Cu}_{30} \mathrm{Al}_{10} \mathrm{Ni}_{5}$ bulk metallic glass studied by an in-situ ultrasonic echography technique, Intermetallics 10(11-12) (2002), pp. 1289-1296.

[24] T. Ichitsubo et al., Ultrasound-induced crystallisation around the glass transition temperature for Pd40 Ni40 $P_{20}$ metallic glass, Acta Mater 52 (2004), pp. 423-429.

[25] C. Bernard et al., submitted .

[26] A. Leonhard et al., Effect of crystalline precipitations on the mechanical behaviour of bulk glass forming Zr-based alloys, NanoStruct Mater 10(5) (1998), pp. 805-817.

[27] V. Keryvin et al., Elastic moduli of a ZrCuAlNi bulk metallic glass from room temperature to complete crystallisation by in situ pulse-echo ultrasonic echography, J Ceram Soc Jpan (in press).

[28] Z. Zhang, V. Keppens, and T. Egami, A simple model to predict the temperature dependence of elastic moduli of bulk metallic glasses, J Appl Phys 102 (2007), p. 123508.

[29] E. Le Bourhis and T. Rouxel, Indentation of glass with temperature, J Non-Cryst Solids 316(1) (2003), pp. $153-159$.

[30] P. Wesseling et al., Preliminary assessment of flow, notch toughness, and high temperature behavior of $\mathrm{Cu}_{60} \mathrm{Zr}_{20} \mathrm{Hf}_{10} \mathrm{Ti}_{10}$ bulk metallic glass, Scripta Materialia 51(2) (2004), pp. 151-154.

[31] http://www-cast3m.cea.fr/cast3m/index.jsp; .

[32] J. Bucaille et al., Determination of plastic properties of metals by instrumented indentation using different sharp indenters, Acta Mater 51 (2003), pp. 1663-1678.

[33] R. Narasimhan, Analysis of indentation of pressure sensitive plastic solids using the expanding cavity model, Mech Mater 36 (2004), pp. 633-645.

[34] K.L. Johnson Contact Mechanics, Cambridge University Press, Cambridge, 1985.

[35] A. Kumaraswamy and B. Venkataraman, Effect of temperature on constraint factor of Ti-6Al-4V under static indentation conditions, Scripta Mater 54(3) (2006), pp. 493-498.

[36] P. Murali and U. Ramamurty, Embrittlement of a bulk metallic glass due to sub-T-g annealing, Acta Materialia 53(5) (2005), pp. 1467-1478.

[37] R. Raghavan, P. Murali, and U. Ramamurty, Ductile to brittle transition in the Zr41.2Ti13.75Cu12.5Ni10Be22.5 bulk metallic glass, Intermetallics 14(8-9) (2006), pp. 1051-1054.

[38] S. Jana et al., Deformation morphology underneath the Vickers indent in a Zr-based bulk metallic glass, Intermetallics 12(10-11) (2004), pp. 1097-1102.

[39] U. Ramamurty et al., Hardness and plastic deformation in a bulk metallic glass, Acta Mater 53(3) (2005), pp. 705717.

[40] R. Conner et al., Shear bands and cracking of metallic glasses in bending, J Appl Phys 94(2) (2003), p. 904.

[41] P. Donovan, A yield criterion for the $P d_{40} N i_{40} P_{20}$ metallic glass, Acta Metall 37(2) (1989), pp. $445-456$.

[42] H.A. Bruck et al., Quasi-static constitutive behavior of $\mathrm{Zr}_{41.2} \mathrm{Ti}_{13.8} \mathrm{Cu}_{12.5} \mathrm{Ni}_{10.0} \mathrm{Be} 22.5$ bulk amorphous alloys, Scripta Metall Mater 30(4) (1994), pp. 429-434.

[43] J.J. Lewandowski and P. Lowhaphandu, Effect of hydrostatic pressure in the flow and fracture of a bulk amorphous metal, Phil Mag 82(17/18) (2002), pp. 3427-3441.

[44] J. Lu and G. Ravichandran, Pressure-dependent flow behaviour of $\mathrm{Zr}_{41.2} \mathrm{Ti}_{13.8} \mathrm{Cu}_{12.5} \mathrm{Ni}_{10.0} \mathrm{Be}_{22.5}$ bulk metallic glass, J Mater Res 18(9) (2003), pp. 2039-2049.

[45] Z.F. Zhang, J. Eckert, and L. Schultz, Difference in compressive and tensile fracture mechanisms of $\mathrm{Zr}_{59} \mathrm{Cu}_{20} \mathrm{Al}_{10} \mathrm{Ni}_{8} \mathrm{Ti}_{3}$, Acta Mater 51 (2003), pp. 1167-1179.

[46] K. Flores and R. Dauskardt, Mode II fracture behavior of a Zr-based bulk metallic glass, J Mech Phys Solids 54(11) (2006), pp. 2418-2435.

[47] A.C. Lund and C.A. Schuh, Yield surface of a simulated metallic glass, Acta Mater 51(18) (2003), pp. 5399-5411.

[48] C. Su and L. Anand, Plane strain indentation of a Zr-based metallic glass: Experiments and numerical simulation, Acta Mater 54(1) (2006), pp. 179-189.

[49] A. Peker and W.L. Johnson, A Highly Processable Metallic Glass: $\mathrm{Zr}_{41.2} \mathrm{Ti}_{13.8} \mathrm{Cu}_{12.5} \mathrm{Ni}_{10.0} \mathrm{Be}_{22.5}$, Appl Phys Letters 63 (1993), p. 2342.

[50] M.L. Vaillant et al., Changes in the mechanical properties of a $\mathrm{Zr}_{55} \mathrm{Cu}_{30} \mathrm{Al}_{10} \mathrm{Ni}_{5}$ bulk metallic glass due to heattreatments below $540^{\circ} \mathrm{C}$, Scripta Mater 47 (2002), pp. 19-23.

[51] V. Keryvin et al., Toughness of $\mathrm{Zr}_{55} \mathrm{Cu}_{30} \mathrm{Al}_{10} \mathrm{Ni}_{5}$ bulk metallic glass for two oxygen levels, J Non-Cryst Solids 352(26-27) (2006), p. 2863. 


\begin{tabular}{cccc}
\hline \hline Glass composition (at.\%) & $\mathrm{T}_{g}(\mathrm{~K})$ & Ref. \\
\cline { 2 - 4 } & $\mathrm{Pd}_{40} \mathrm{Ni}_{40} \mathrm{P}_{20}$ & 590 & {$[4]$} \\
$\mathrm{Zr}_{41.2} \mathrm{Ti}_{13.75} \mathrm{Cu}_{12.5} \mathrm{Ni}_{10} \mathrm{Be}_{22.5}$ & 625 & {$[49]$} \\
$\mathrm{Zr}_{55} \mathrm{Cu}_{30} \mathrm{Al}_{10} \mathrm{Ni}_{5}$ & 680 & {$[50,51]$} \\
\hline \hline
\end{tabular}

Table 1. Composition and glass transition temperatures $\mathrm{T}_{g}$ of the three amorphous alloys studied. 


\begin{tabular}{cccccc}
\hline \hline Glass composition & $Y_{c, T}$ & $H_{, T}$ & $E_{, T}$ & $G_{, T}$ & $\epsilon_{y, T}\left(10^{-6} / \mathrm{K}\right)$ \\
\hline $\mathrm{Pd}_{40} \mathrm{Ni}_{40} \mathrm{P}_{20}$ & 1.74 & 2.26 & 27.3 & 10.8 & 13.4 \\
$\mathrm{Zr}_{41.2} \mathrm{Ti}_{13.75} \mathrm{Cu}_{12.5} \mathrm{Ni}_{10} \mathrm{Be}_{22.5}$ & 2.26 & 2.46 & 10.8 & 4 & 10.6 \\
$\mathrm{Zr}_{55} \mathrm{Cu}_{30} \mathrm{Al}_{10} \mathrm{Ni}_{5}$ & 2.13 & 2.08 & 21.7 & 6.61 & 9.91 \\
\hline \hline
\end{tabular}

Table 2. Temperature dependence of mechanical properties of the bulk metallic glasses studied in this paper. Slopes, calculated from linear regressions, are indicated for respectively $Y_{c}$ (true compressive yield stress), $H$ (Meyer's hardness), $E$ (Young's modulus), $G$ (shear modulus) and $\epsilon_{y}$ (true yield strain) and printed as $a, T$ where $a$ is one these four properties. If not indicated, slopes are in $\mathrm{MPa} / \mathrm{K}$. 


\begin{tabular}{ccccccc}
\hline \hline $\mathrm{T}(\mathrm{K})$ & $\mathrm{E}(\mathrm{GPa})$ & $\nu(-)$ & $\mathrm{Y}_{c}(\mathrm{GPa})$ & $\mathrm{Y}_{t}(\mathrm{GPa})$ & $\alpha\left(^{\circ}\right)$ & $\mathrm{C}(-)$ \\
\hline 293 & 104 & 0.41 & 1.75 & 1.6 & 7.65 & 3.05 \\
323 & 103 & 0.41 & 1.70 & 1.51 & 10 & 3.18 \\
373 & 102 & 0.41 & 1.66 & 1.53 & 7.65 & \\
& & & & 1.39 & 15 & 3.4 \\
423 & \multirow{2}{*}{100} & 0.41 & \multirow{2}{*}{1.5} & 1.39 & 7.65 & \\
& & & & 1.25 & 15 & \\
& & & & 1.14 & 22 & 3.9 \\
473 & \multirow{2}{*}{98} & 0.41 & 1.43 & 1.43 & 0 & \\
& & & & 1.32 & 7.65 & \\
\hline \hline
\end{tabular}

Table 3. Mechanical parameters used in the Finite Element Analyses for PdNiP as function of temperature T. E, $\nu, \mathrm{Y}_{c}, \mathrm{Y}_{t}$ and $\alpha$ stand respectively for Young's modulus, Poisson's ratio, compressive yield stress, tensile yield stress, friction angle of the DP model (1). Added are estimations of constraint factor $C$ using $\alpha$. 

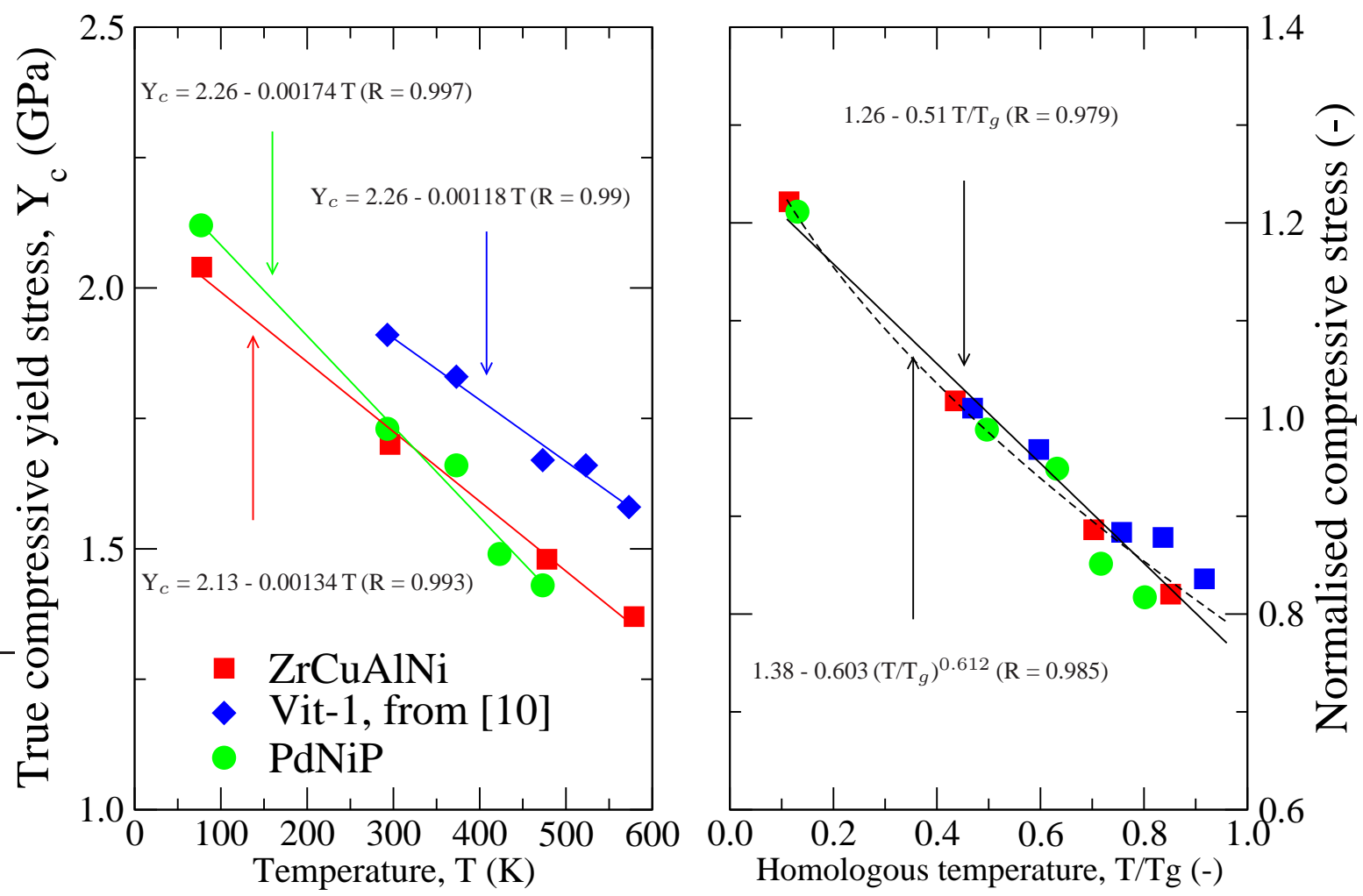

Figure 1. Temperature dependence of true compressive yield stress for the three amorphous alloys (left) and reduced plot $\mathrm{Y}_{c}$ $\left(\mathrm{T} / \mathrm{T}_{g}\right) / \mathrm{Y}_{c}\left(\mathrm{~T} / \mathrm{T}_{g}=0.5\right)$ vs. homologous temperature $T / T_{g}$ (right). Regression fits for each data set are indicated. 


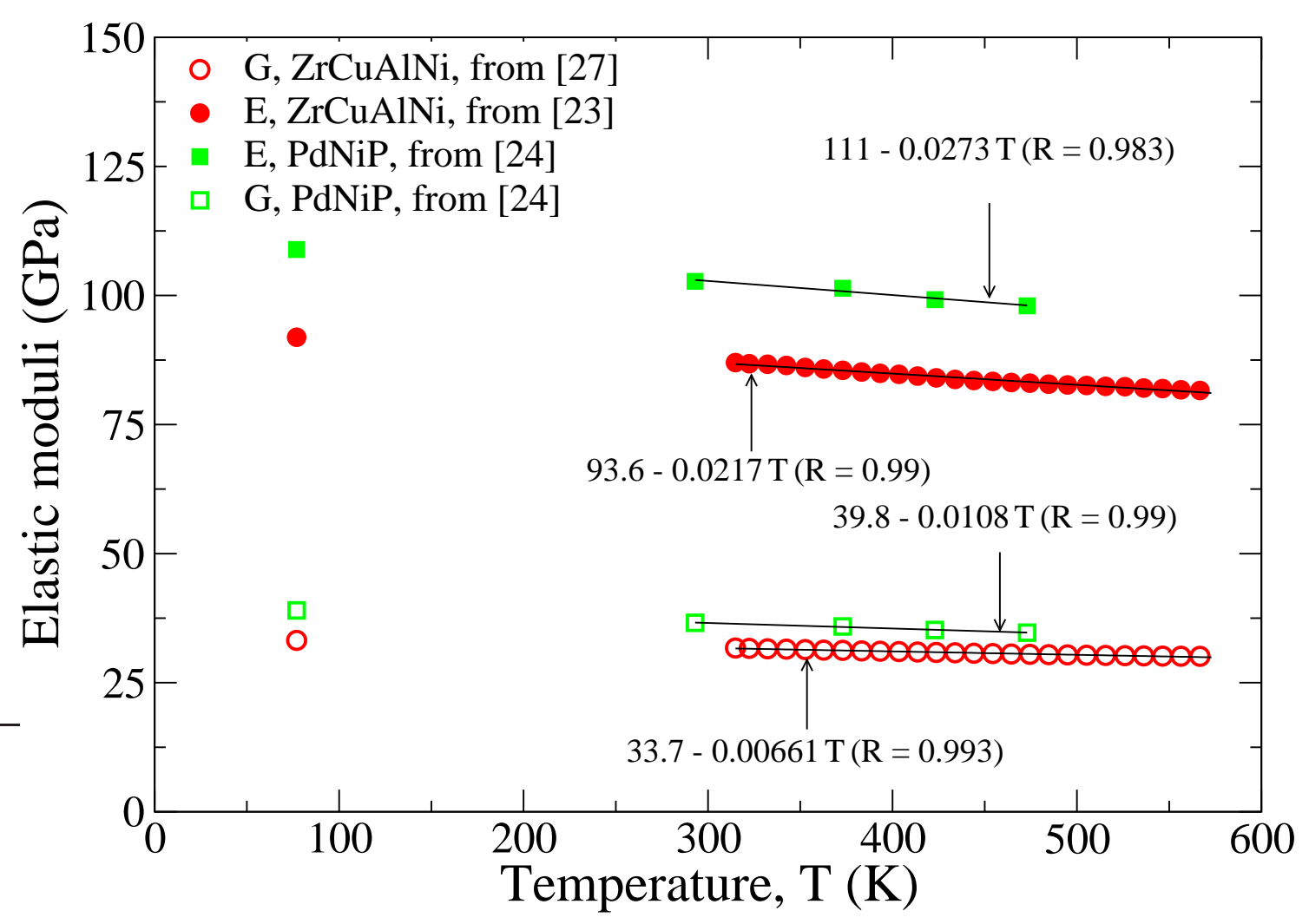

Figure 2. Temperature dependence of Young's modulus and shear modulus for $\mathrm{ZrCuAlNi}$ and PdNiP: values at $77 \mathrm{~K}$ are extrapolated. Linear regression fits for each data set are indicated. 

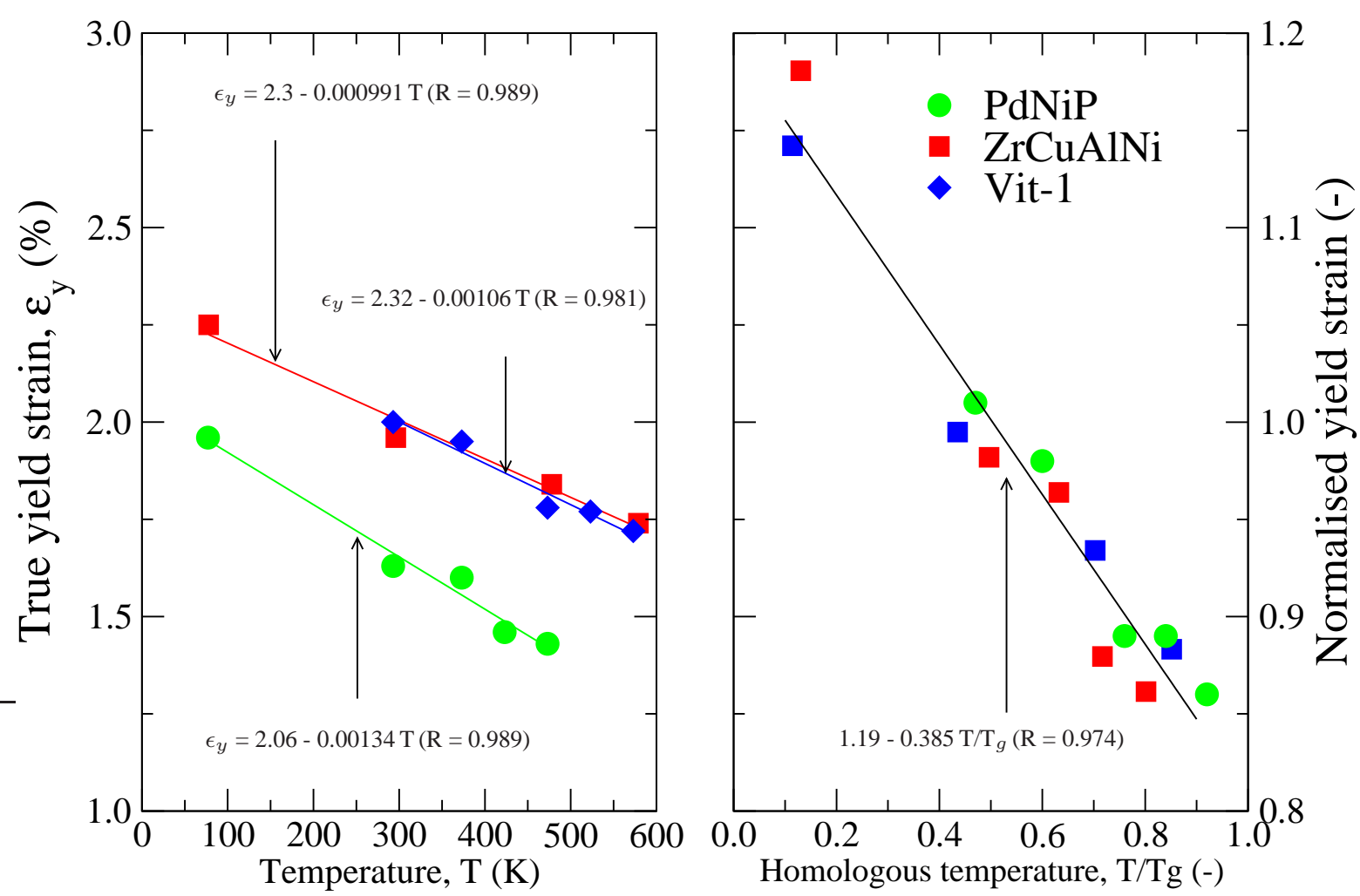

Figure 3. Temperature dependence of yield strain for the three amorphous alloys (left) and reduced plot $\epsilon_{y}\left(\mathrm{~T} / \mathrm{T}_{g}\right) / \epsilon_{y}\left(\mathrm{~T} / \mathrm{T}_{g}=0.5\right)$ vs. homologous temperature $T / T_{g}$ (right). Linear regression fits for each data set are indicated. 

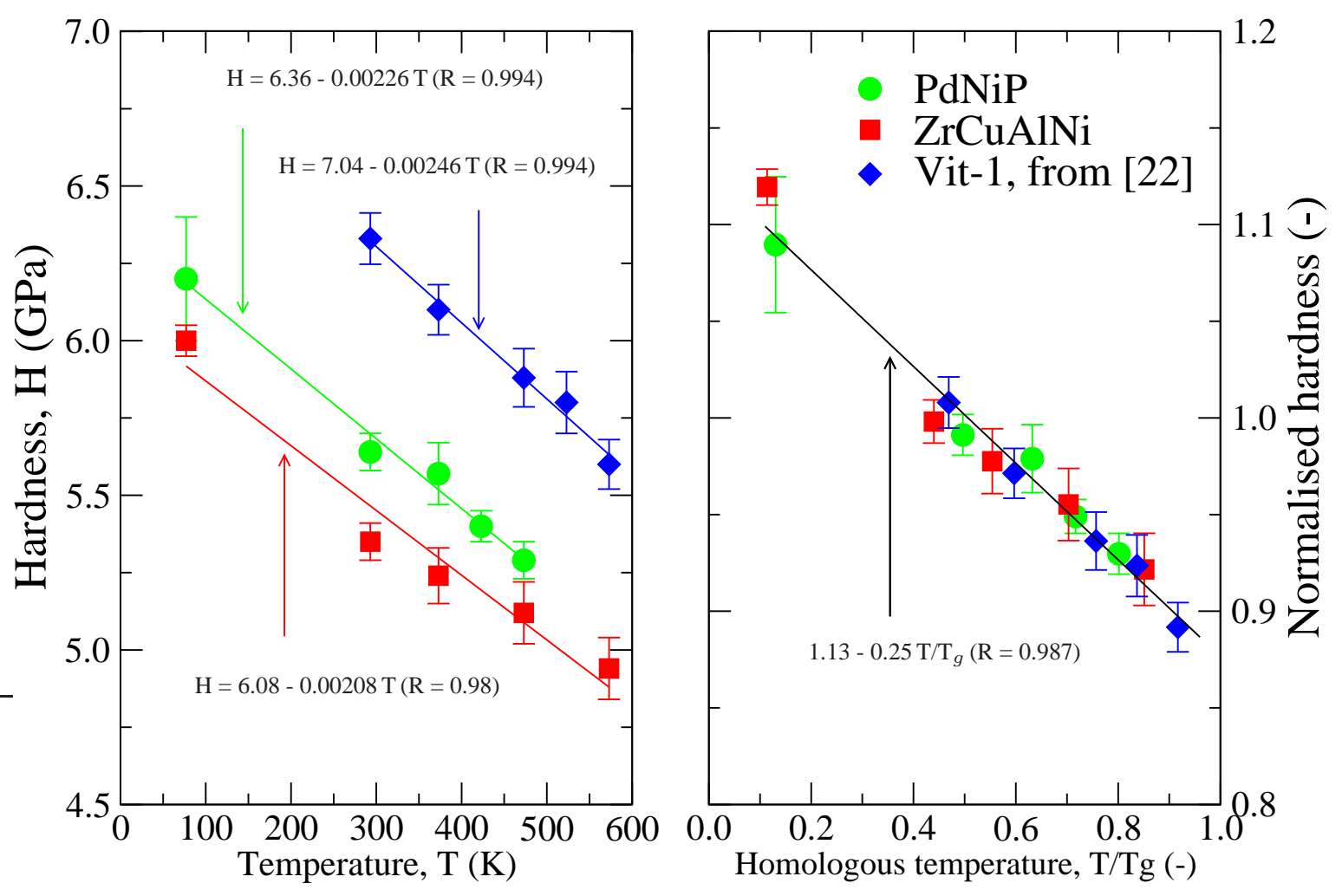

Figure 4. Temperature dependence of Meyer's hardness (mean contact pressure) for the three amorphous alloys (left) and reduced plot $\mathrm{H}\left(\mathrm{T} / \mathrm{T}_{g}\right) / \mathrm{H}\left(\mathrm{T} / \mathrm{T}_{g}=0.5\right)$ vs. homologous temperature $T / T_{g}$. Linear regression fits for each data set are indicated. 


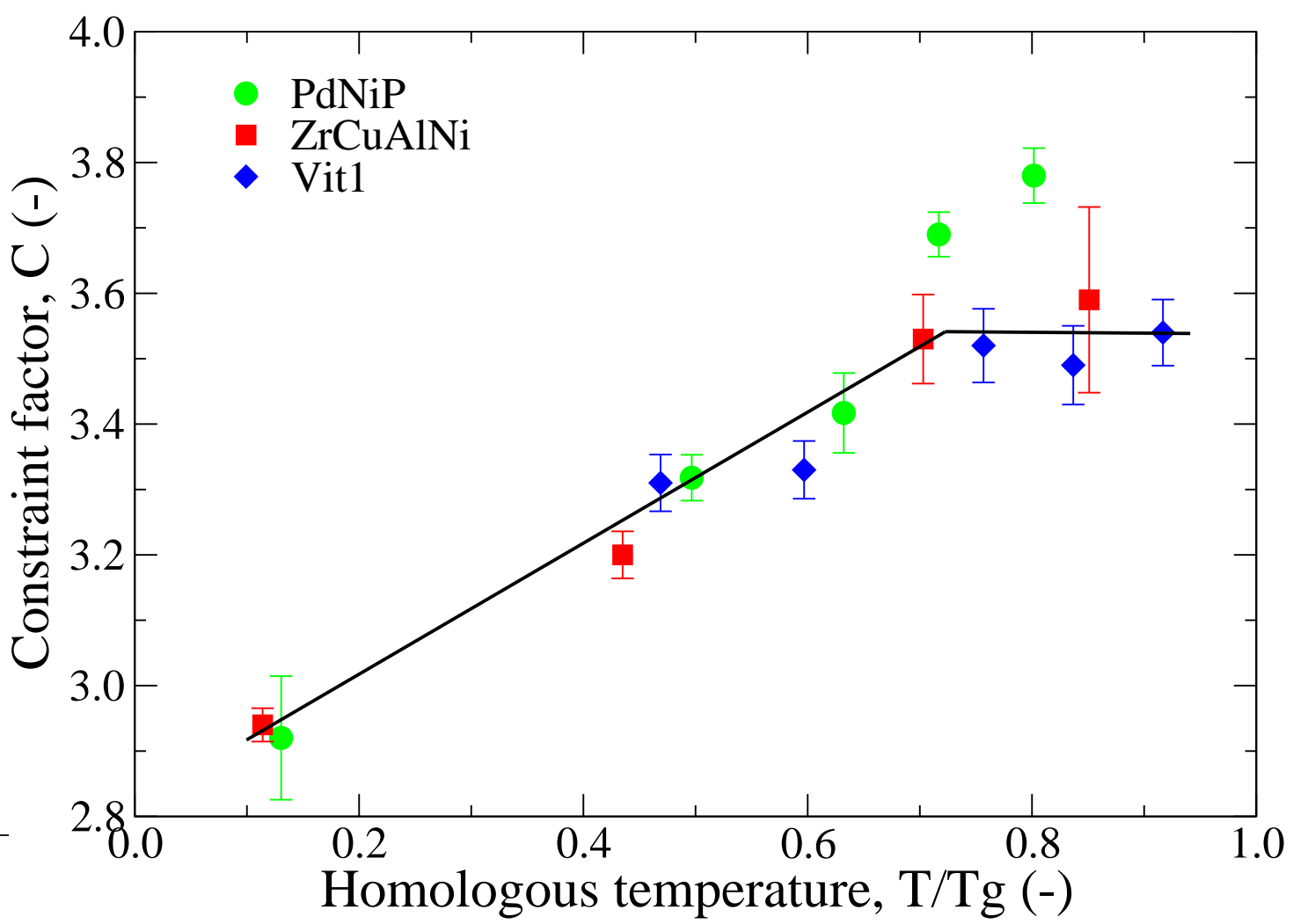

Figure 5. Constraint factor variations for the three amorphous alloys as a function of homologous temperature $T / T_{g}$. The solid lines are presented only to highlight trends. 


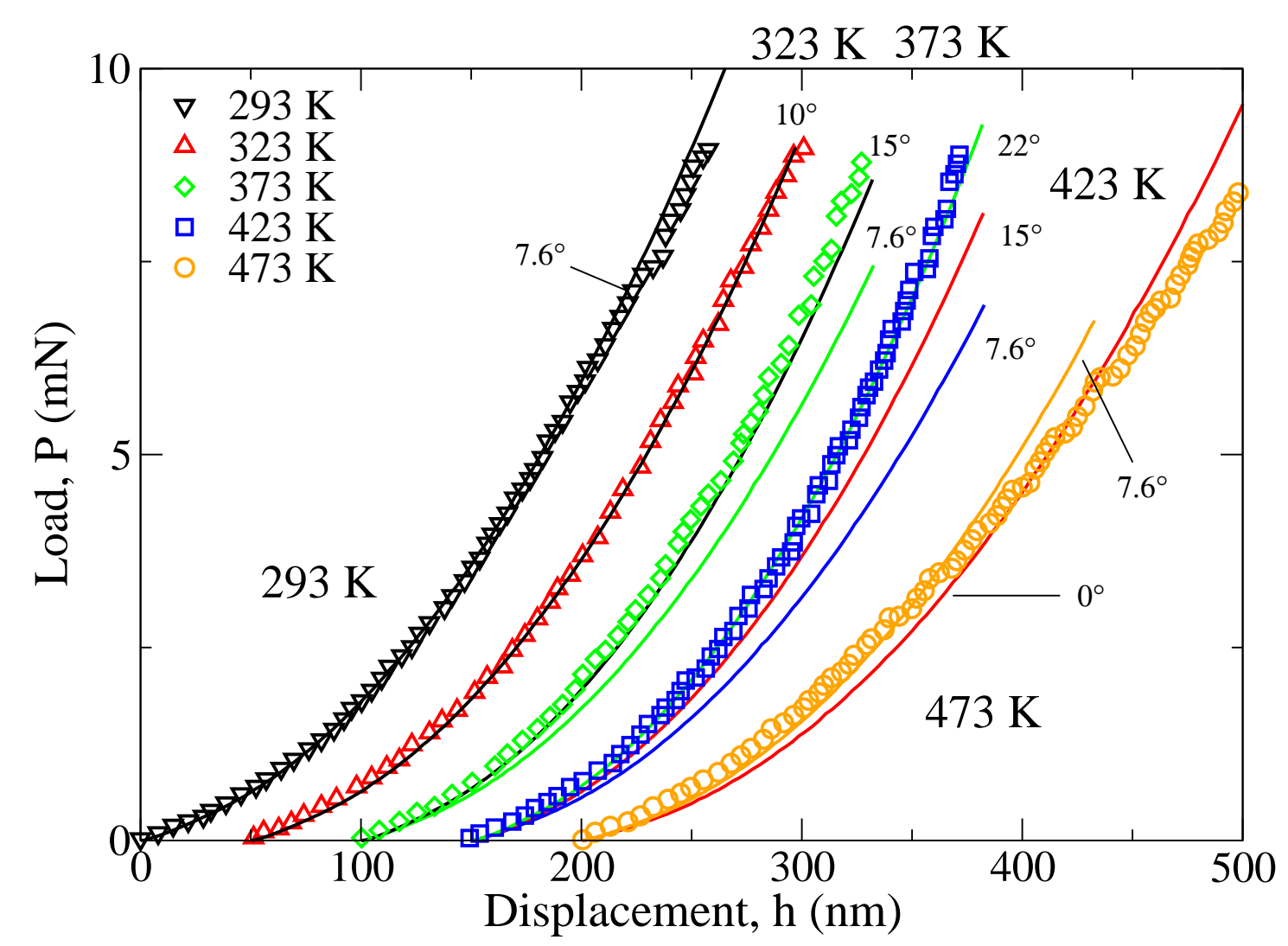

Figure 6. Comparison of experimental nanoindentation load-displacement data (taken from [15], open symbols) on PdNiP and
Finite Element Analyses using the Drucker-Prager model for different friction angles $\alpha$ (straight lines) and different temperatures.

Figure 6. Comparison of experimental nanoindentation load-displacement data (taken from [15], open symbols) on PdNiP and
Finite Element Analyses using the Drucker-Prager model for different friction angles $\alpha$ (straight lines) and different temperatures. The origin of each curve has been offset for sake of clarity.

(1)




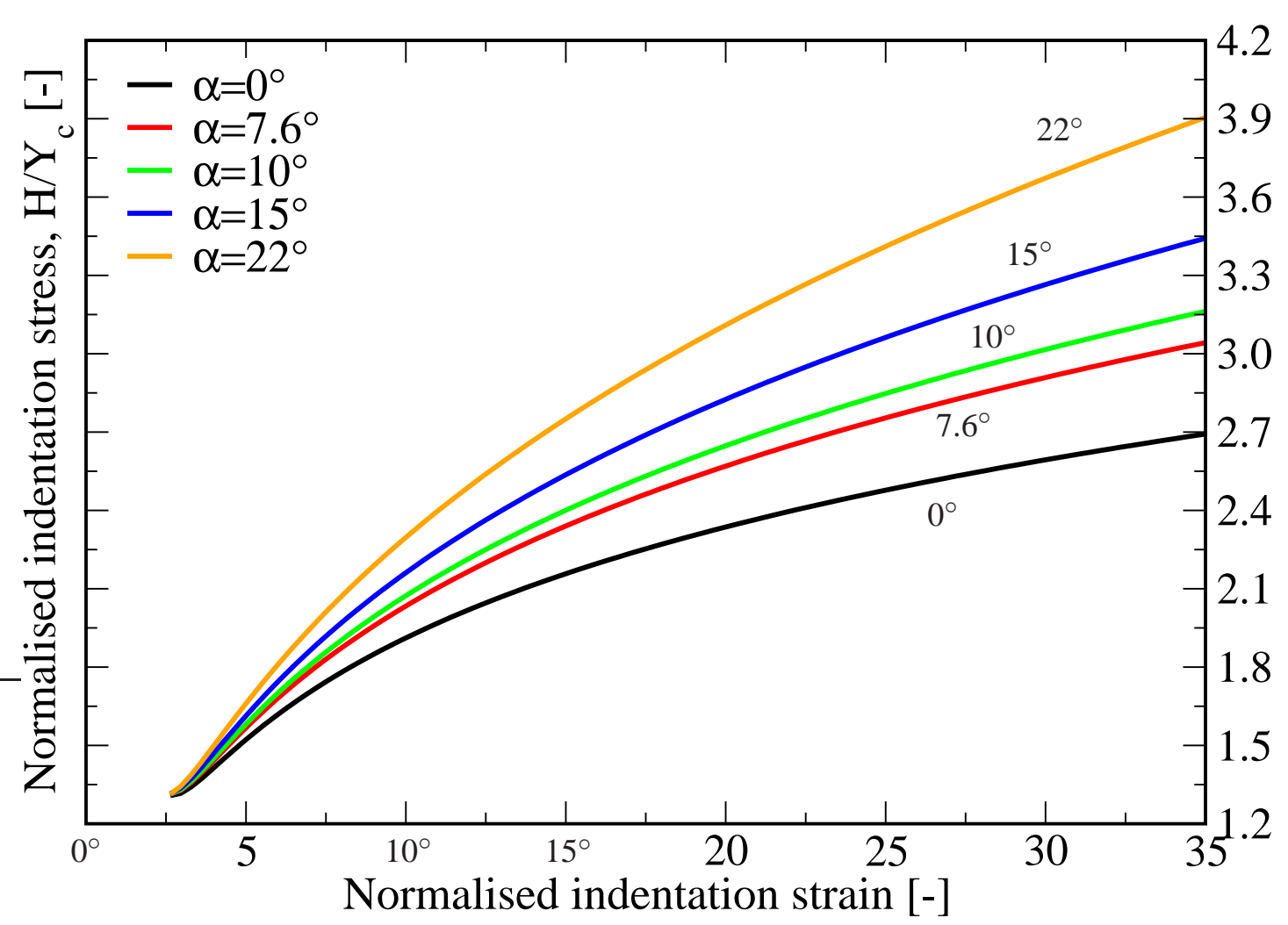

Figure 7. Normalised indentation stress vs. normalised indentation strain curves for different friction angles $\alpha$ by using the DP yield criterion, for PdNiP (adapted from [33]). 


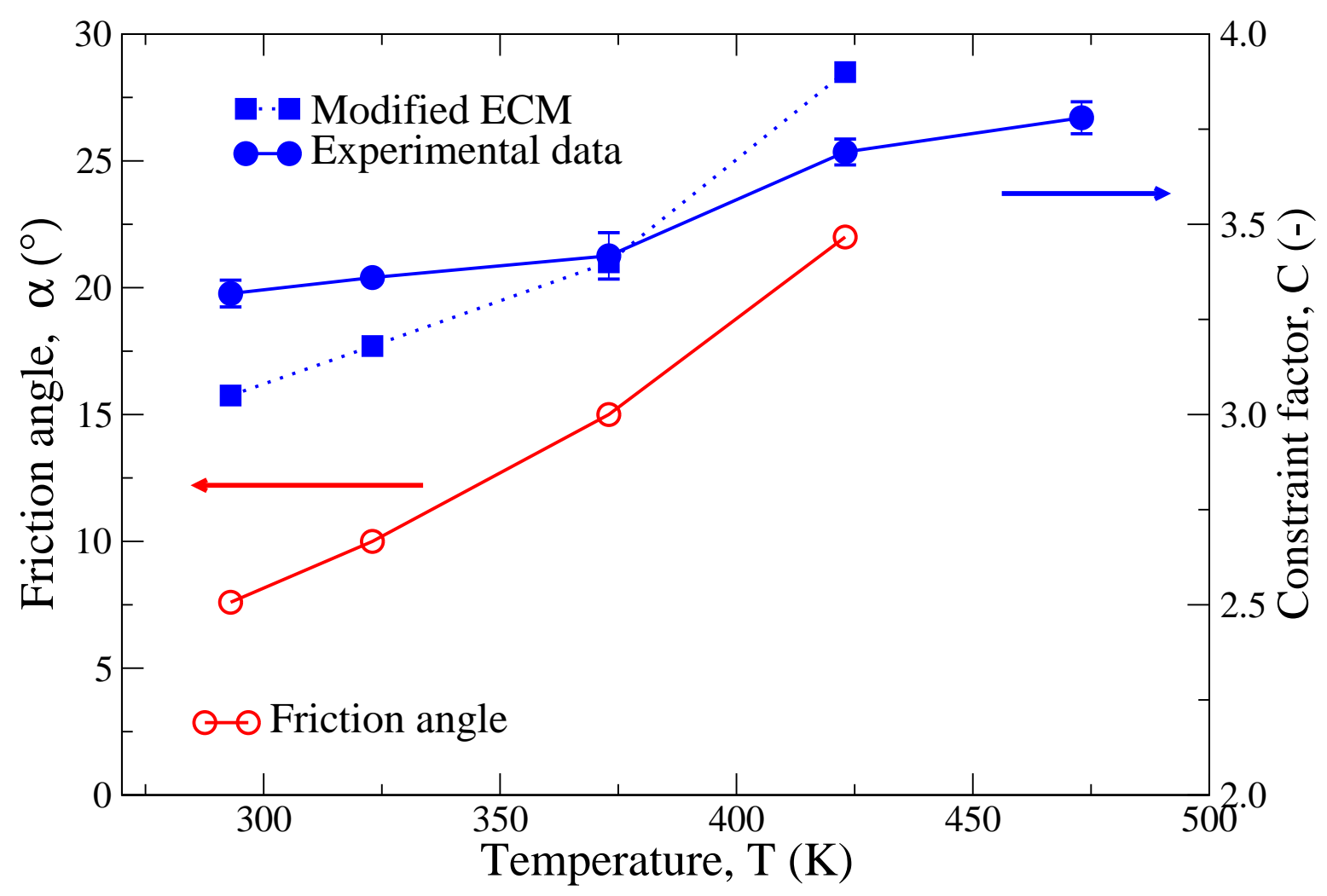

Figure 8. Temperature dependence of friction angle $\alpha$ (left, open symbols) and constraint factor (right, closed symbols) for PdNiP: experimental data (circle) and modified expanding cavity model estimations (square). 


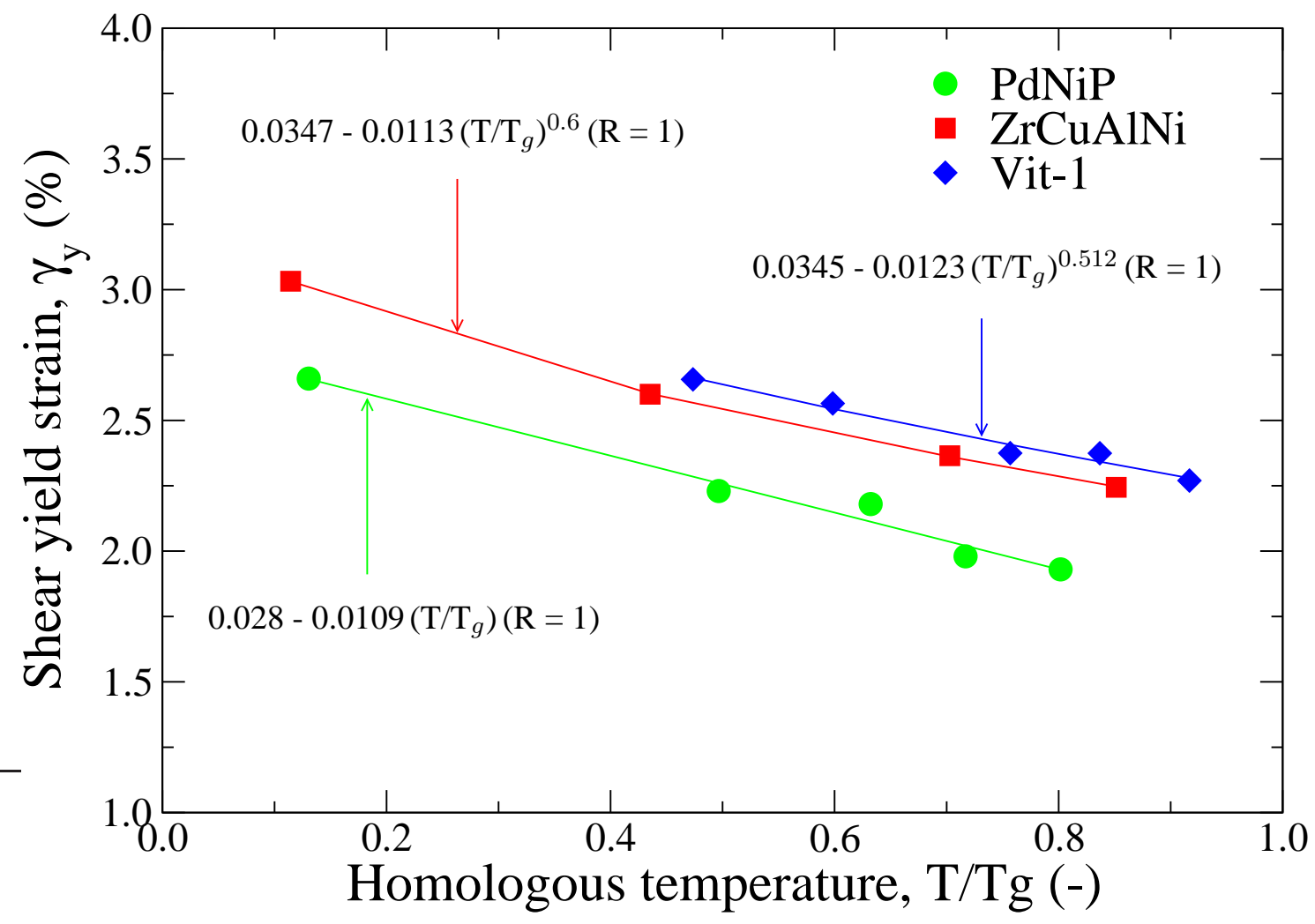

Figure 9. Temperature dependence of shear yield strain for the three amorphous alloys $\mathrm{ZrCuAlNi}$, PdNiP and Vit-1: $T / T_{g}$ is the homologous temperature. Regression fits for each data set are indicated. 


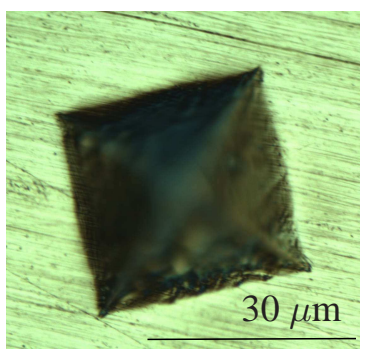

(a)

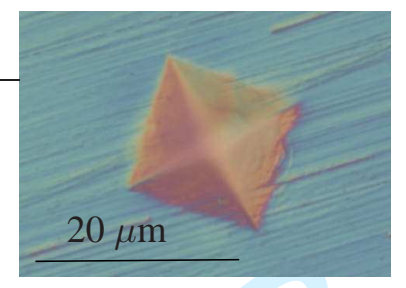

(d)

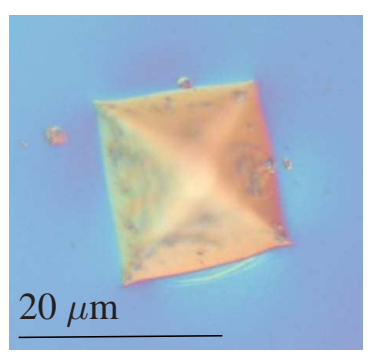

(b)

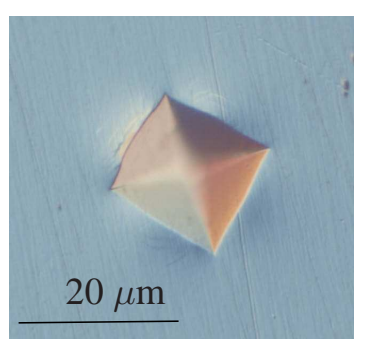

(e)

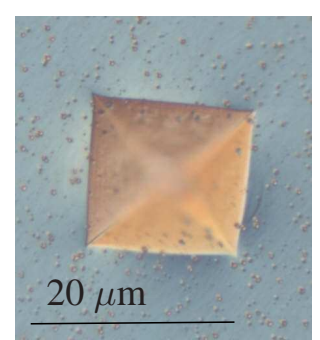

(c)

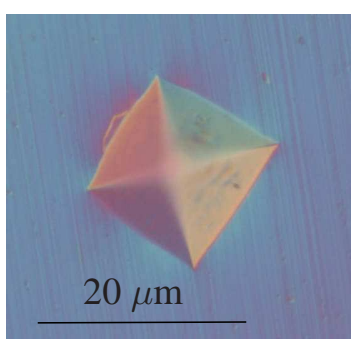

(f)

Figure 10. $5 \mathrm{~N}$ indentations for ZrCuAlNi (top) - (a) $77 \mathrm{~K}$, (b) $293 \mathrm{~K}$, (c) $573 \mathrm{~K}-$ and PdNiP (bottom) - (d) $77 \mathrm{~K}$, (e) $293 \mathrm{~K}$, (f) 473 $\mathrm{K}$. 
Page 27 of 38

Philosophical Magazine \& Philosophical Magazine Letters

REFERENCES

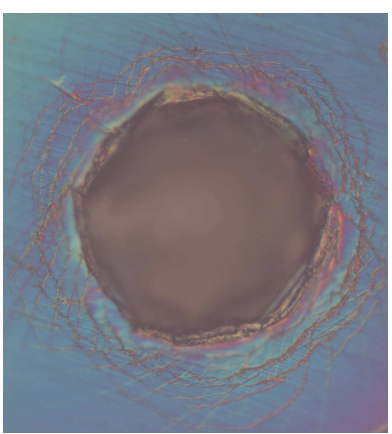

(a)

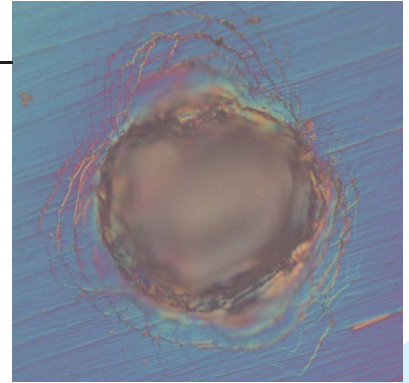

(d)

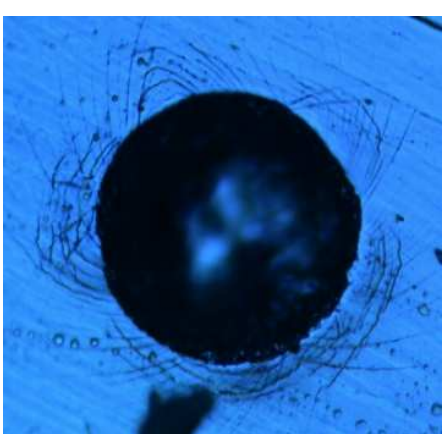

(b)

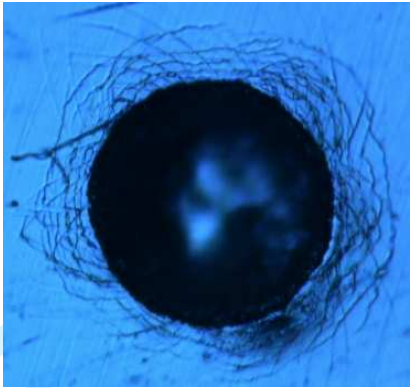

(e)

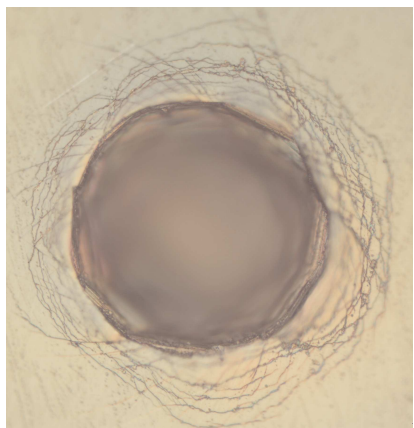

(c)

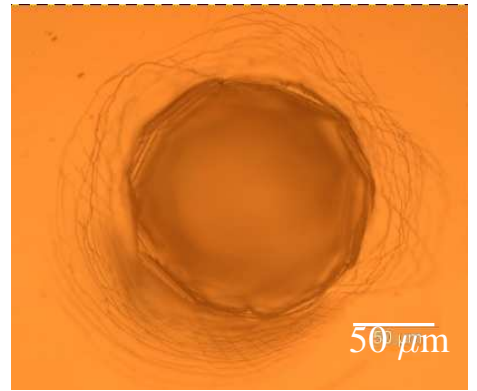

(f)

Figure 11. $50 \mathrm{~N} 90^{\circ}$ conical indentations for ZrCuAlNi (top) - (a) $77 \mathrm{~K}$, (b) $293 \mathrm{~K}$, (c) $573 \mathrm{~K}$ - and PdNiP (bottom) - (d) $77 \mathrm{~K}$, (e) $293 \mathrm{~K}$, (f) $473 \mathrm{~K}$. 


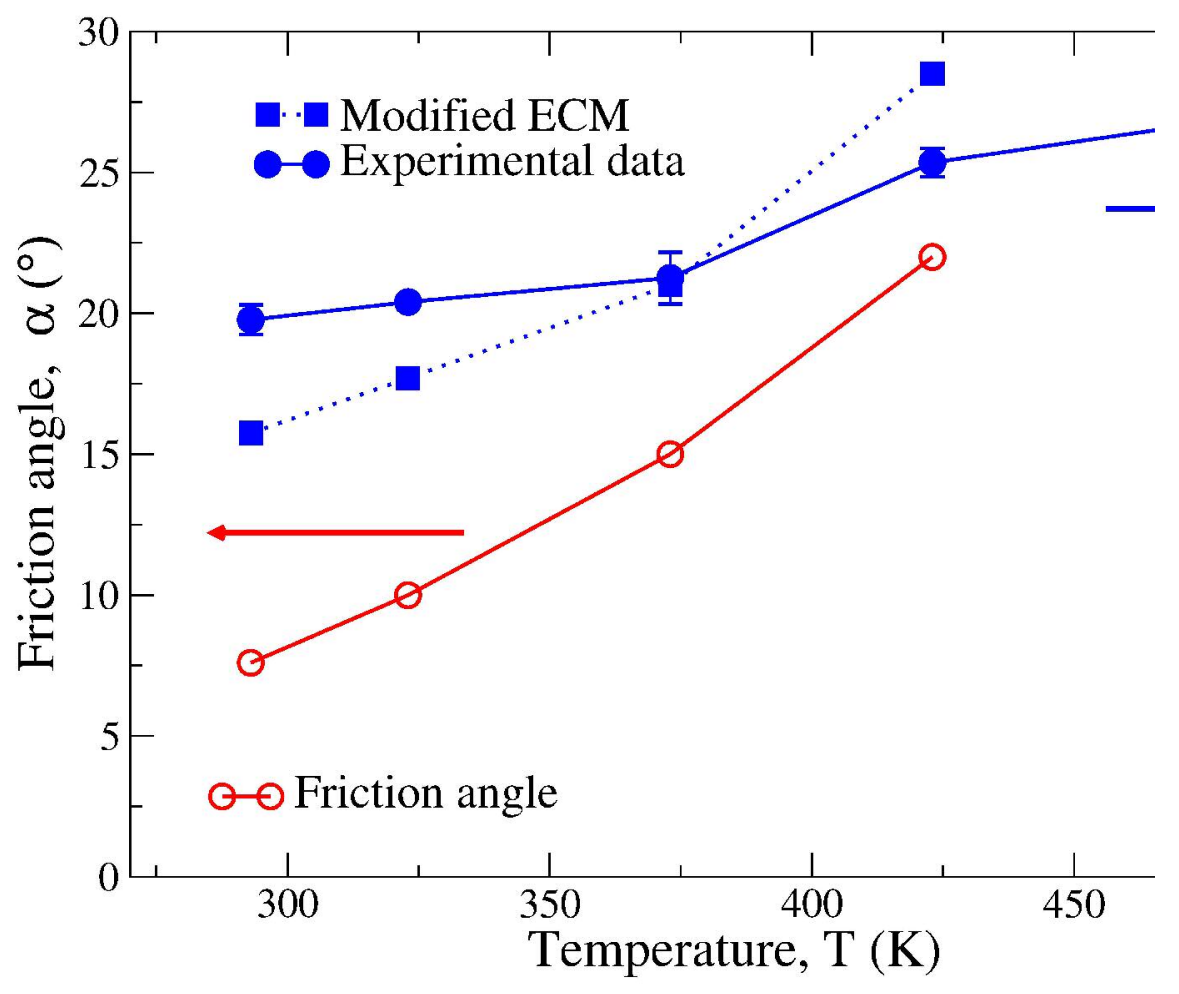

$215 \times 279 m m(600 \times 600$ DPI $)$ 


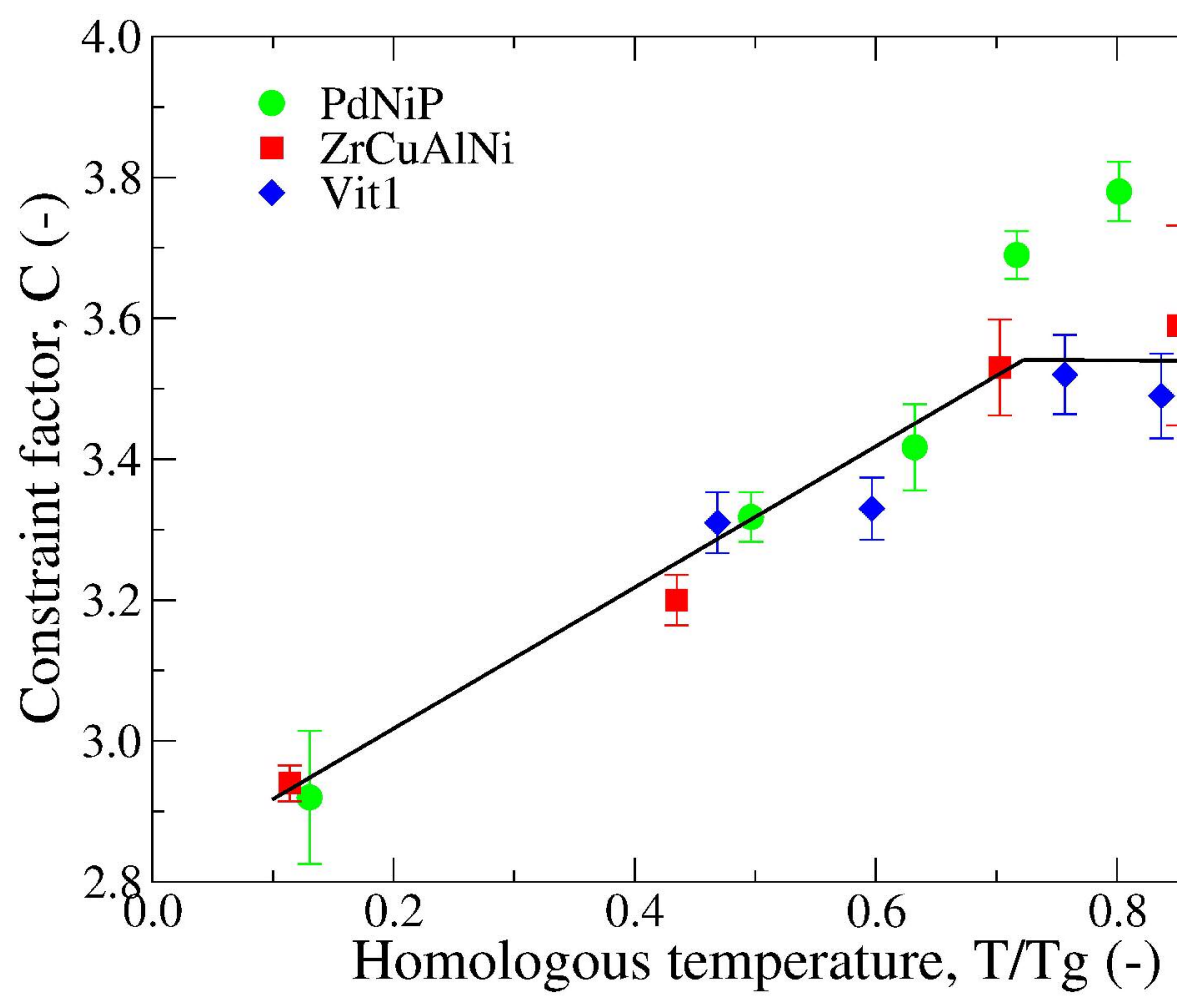

$215 \times 279 m m(600 \times 600$ DPI $)$ 


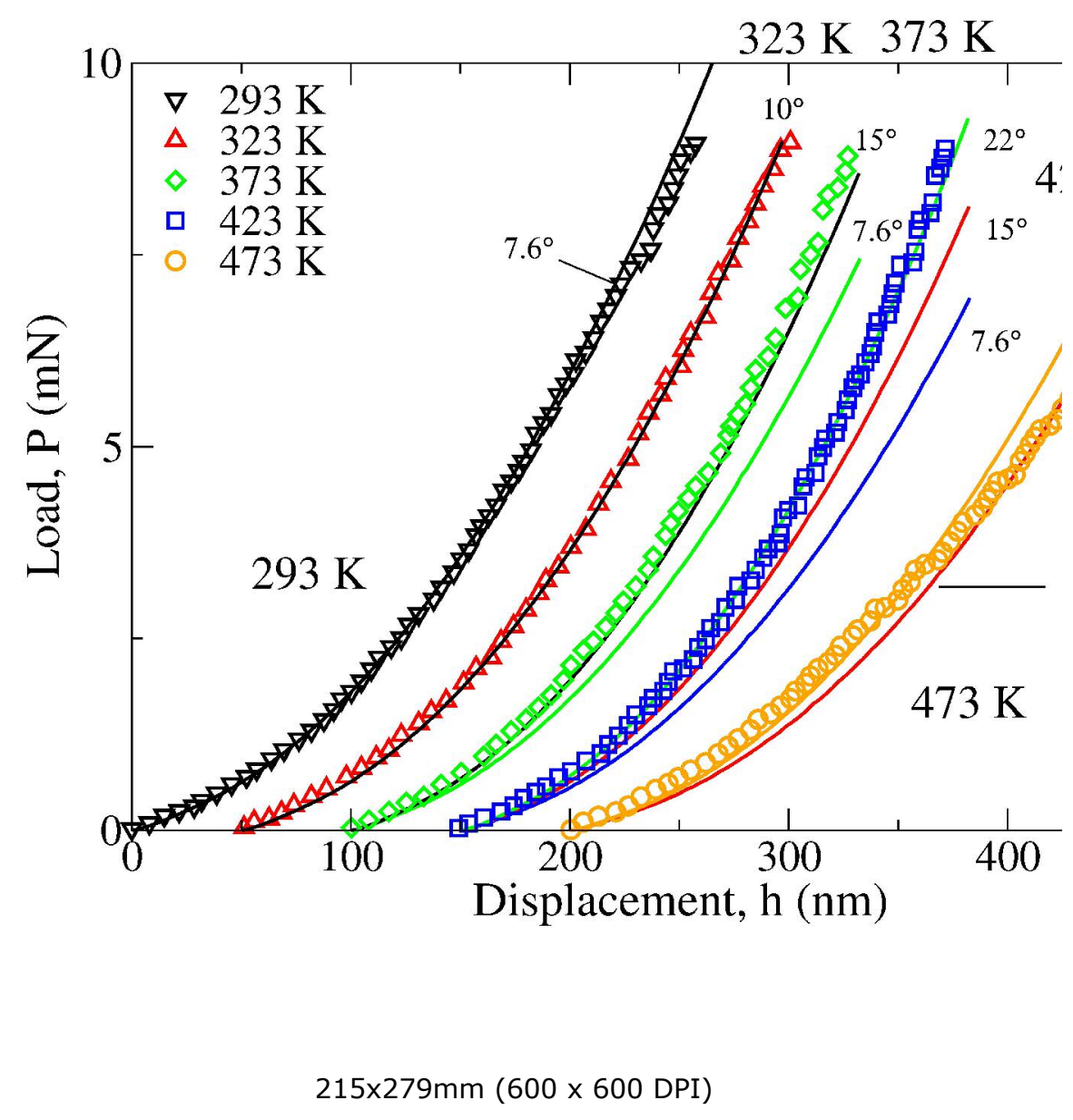

http://mc.manuscriptcentral.com/pm-pml 

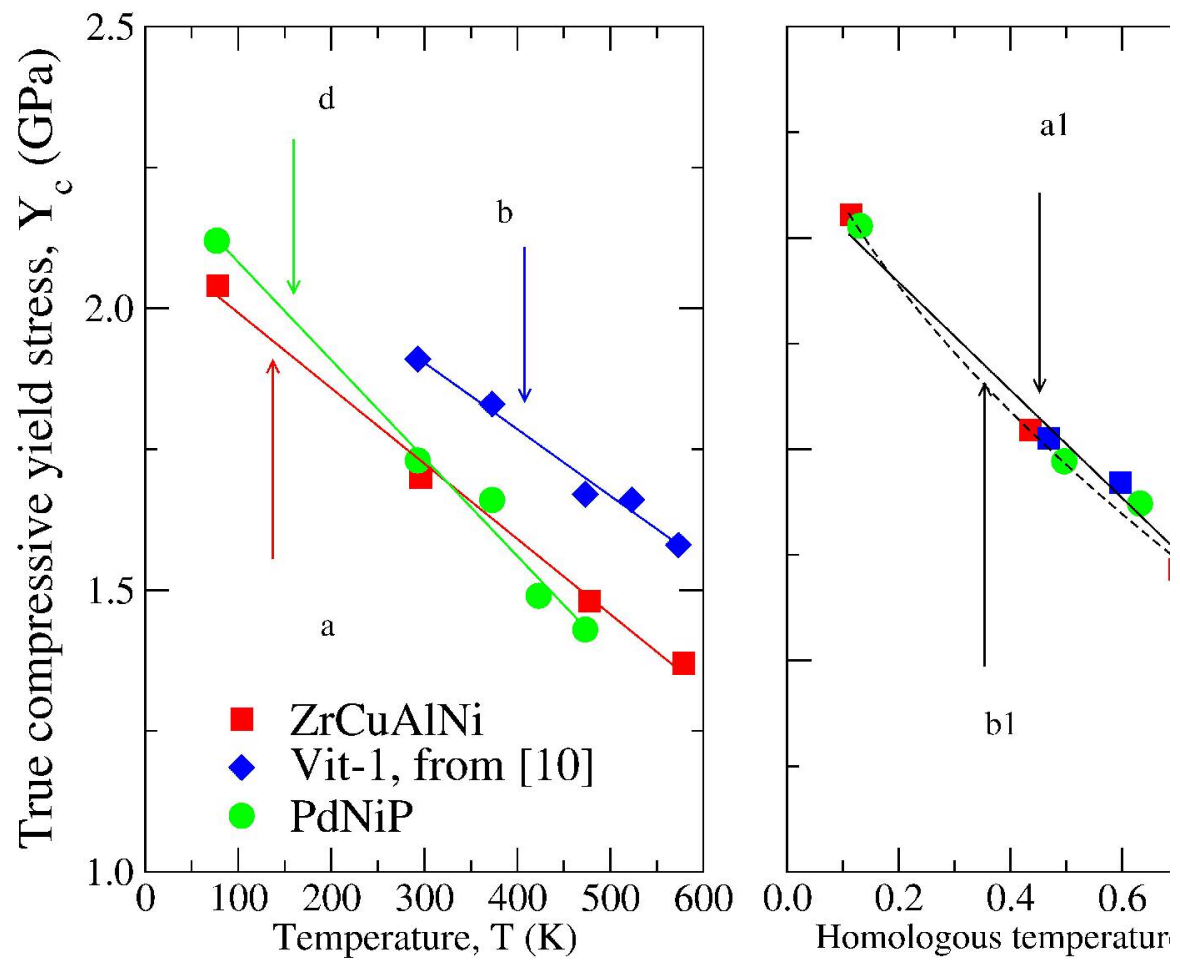

$215 \times 279 \mathrm{~mm}(600 \times 600 \mathrm{DPI})$ 

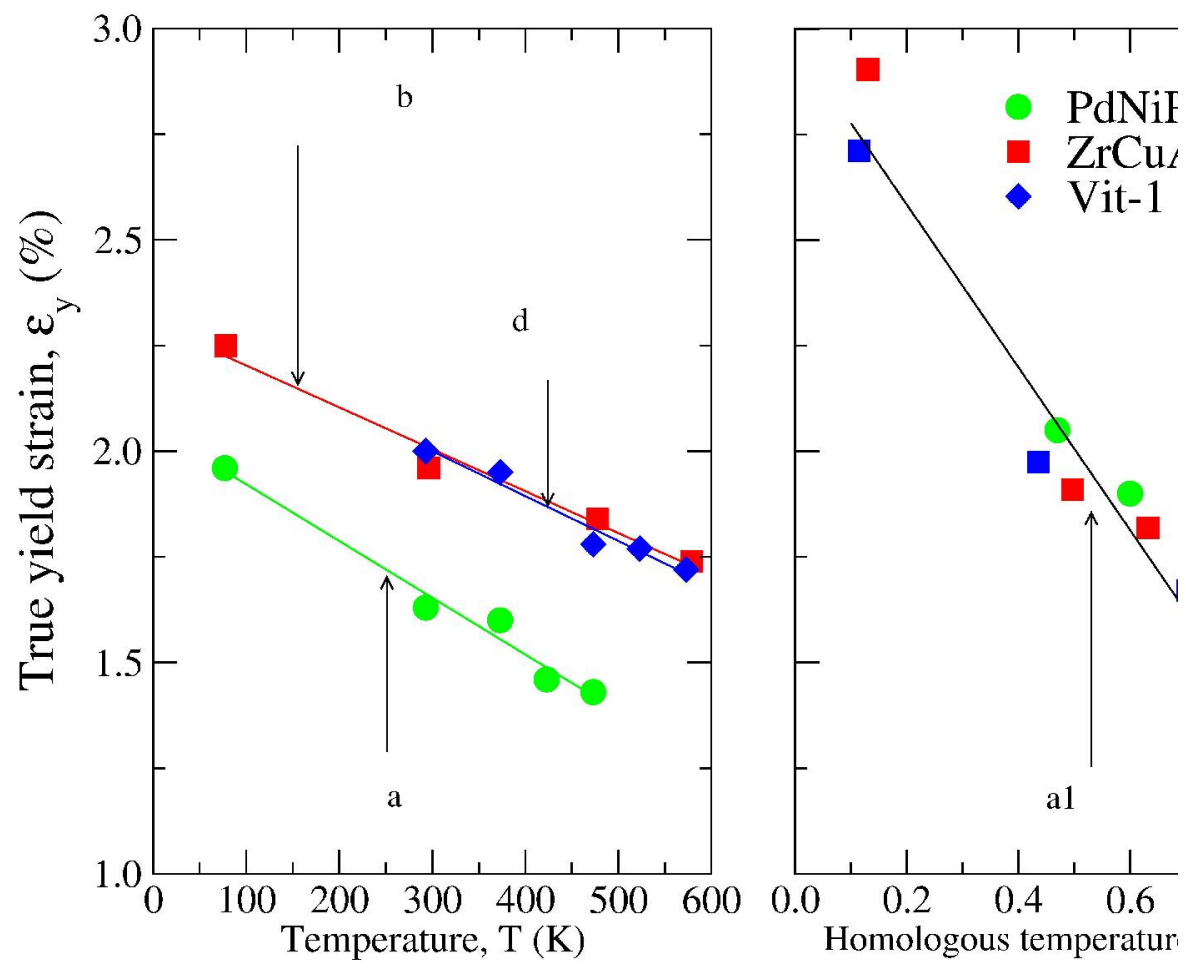

$215 \times 279 \mathrm{~mm}(600 \times 600 \mathrm{DPI})$

http://mc.manuscriptcentral.com/pm-pml 

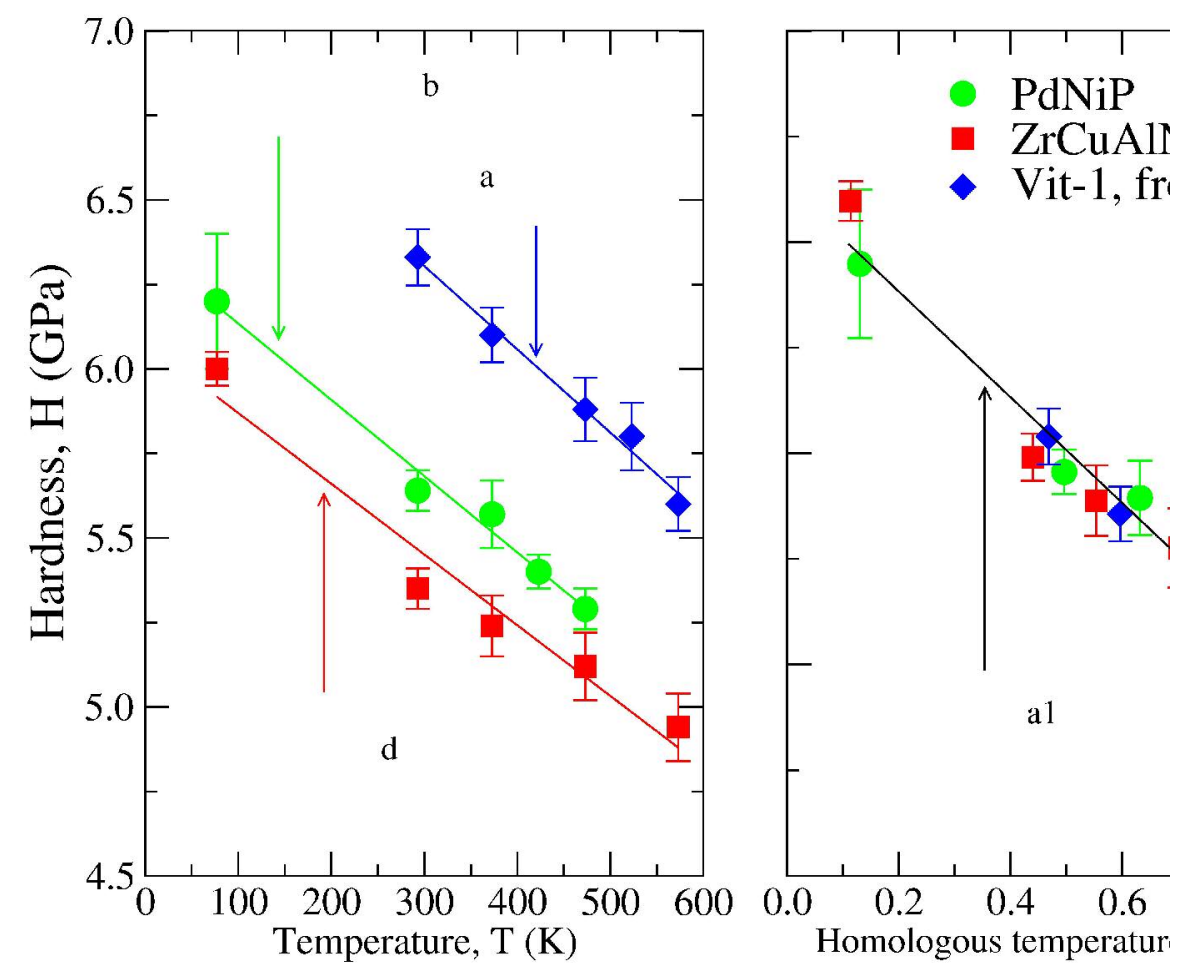

$215 \times 279 \mathrm{~mm}(600 \times 600 \mathrm{DPI})$ 


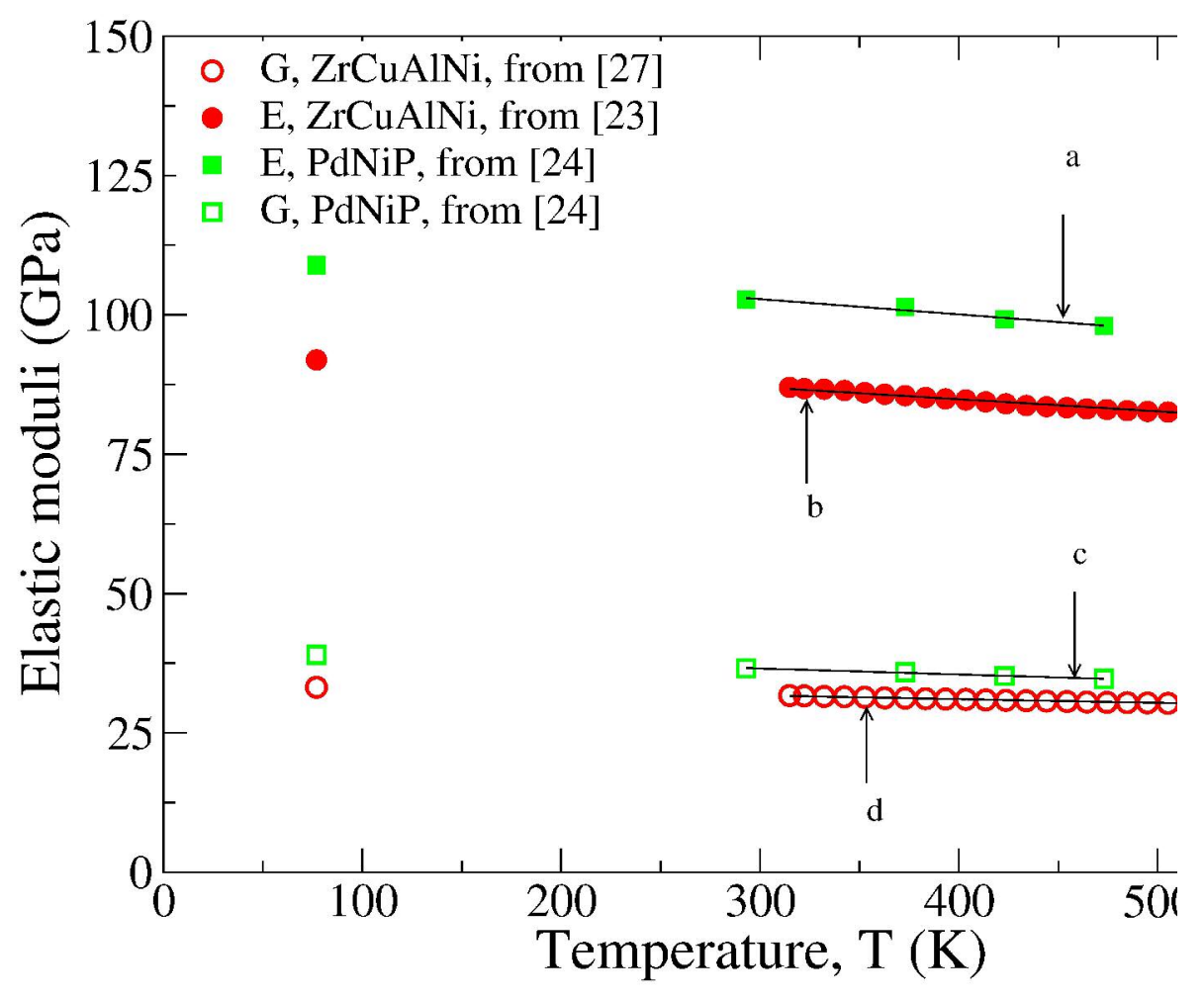

$215 \times 279 m m(600 \times 600$ DPI $)$ 


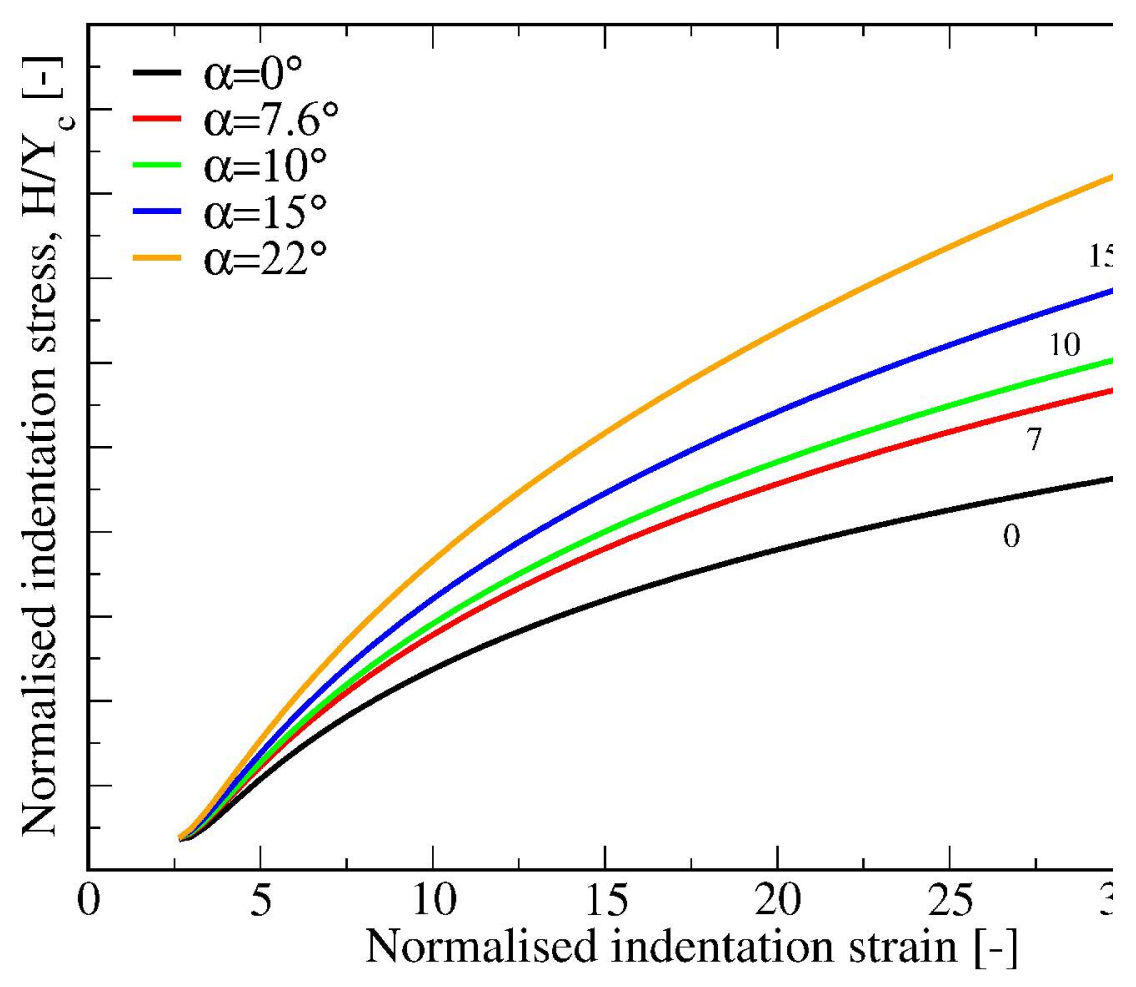

$215 \times 279 \mathrm{~mm}(600 \times 600 \mathrm{DPI})$ 


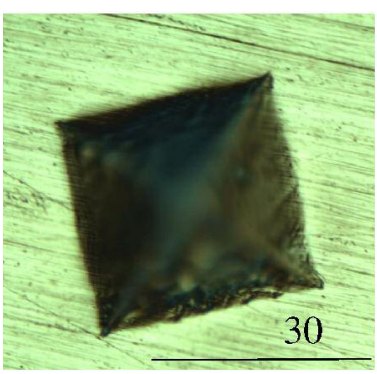

(a)

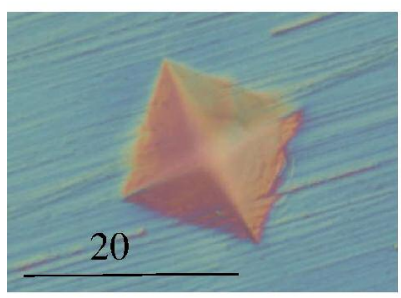

(d)

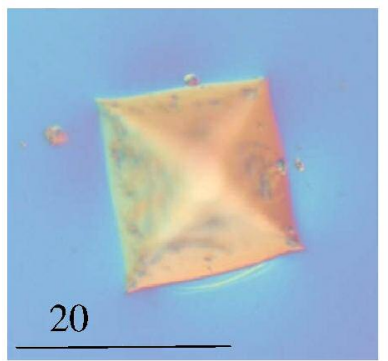

(b)

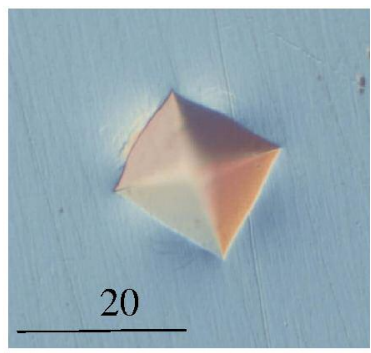

(e)

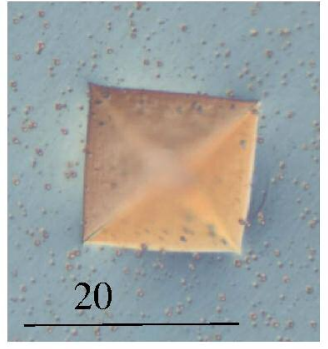

(c)

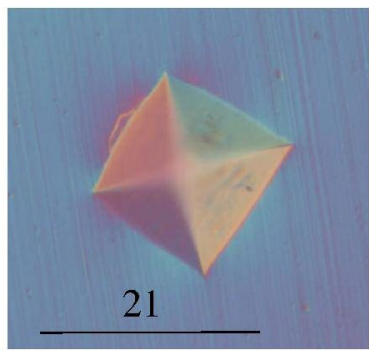

(f)

$125 \times 96 \mathrm{~mm}(600 \times 600 \mathrm{DPI})$ 


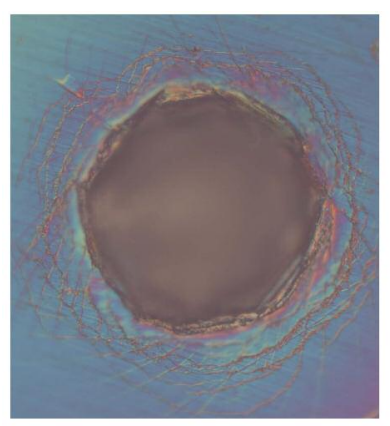

(a)

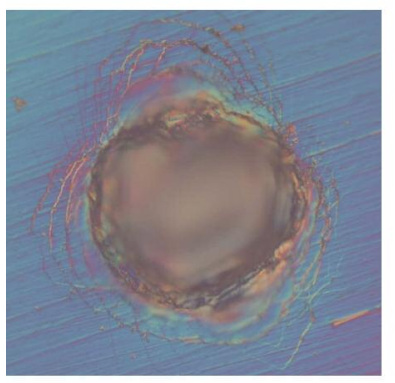

(d)

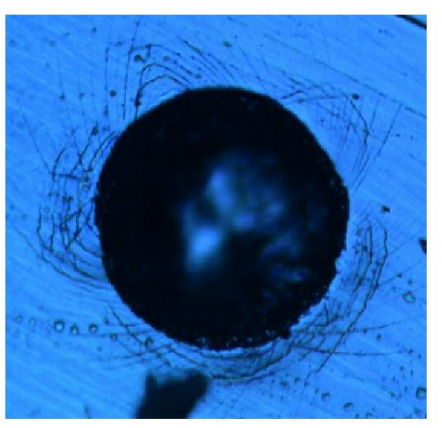

(b)

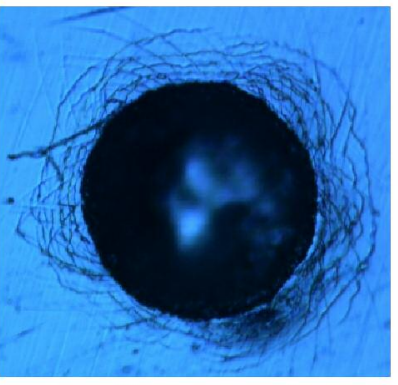

(e)

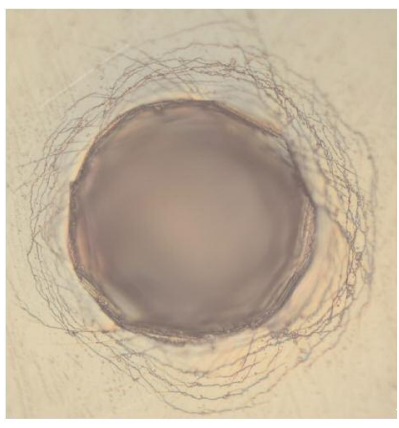

(c)

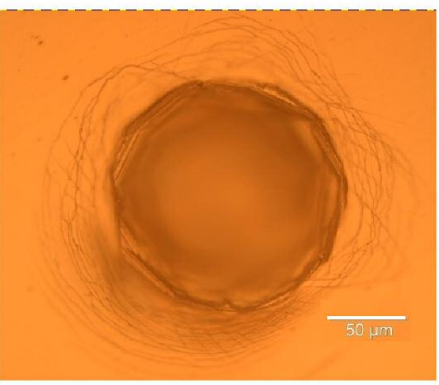

(f)

$263 \times 182 \mathrm{~mm}(600 \times 600 \mathrm{DPI})$ 


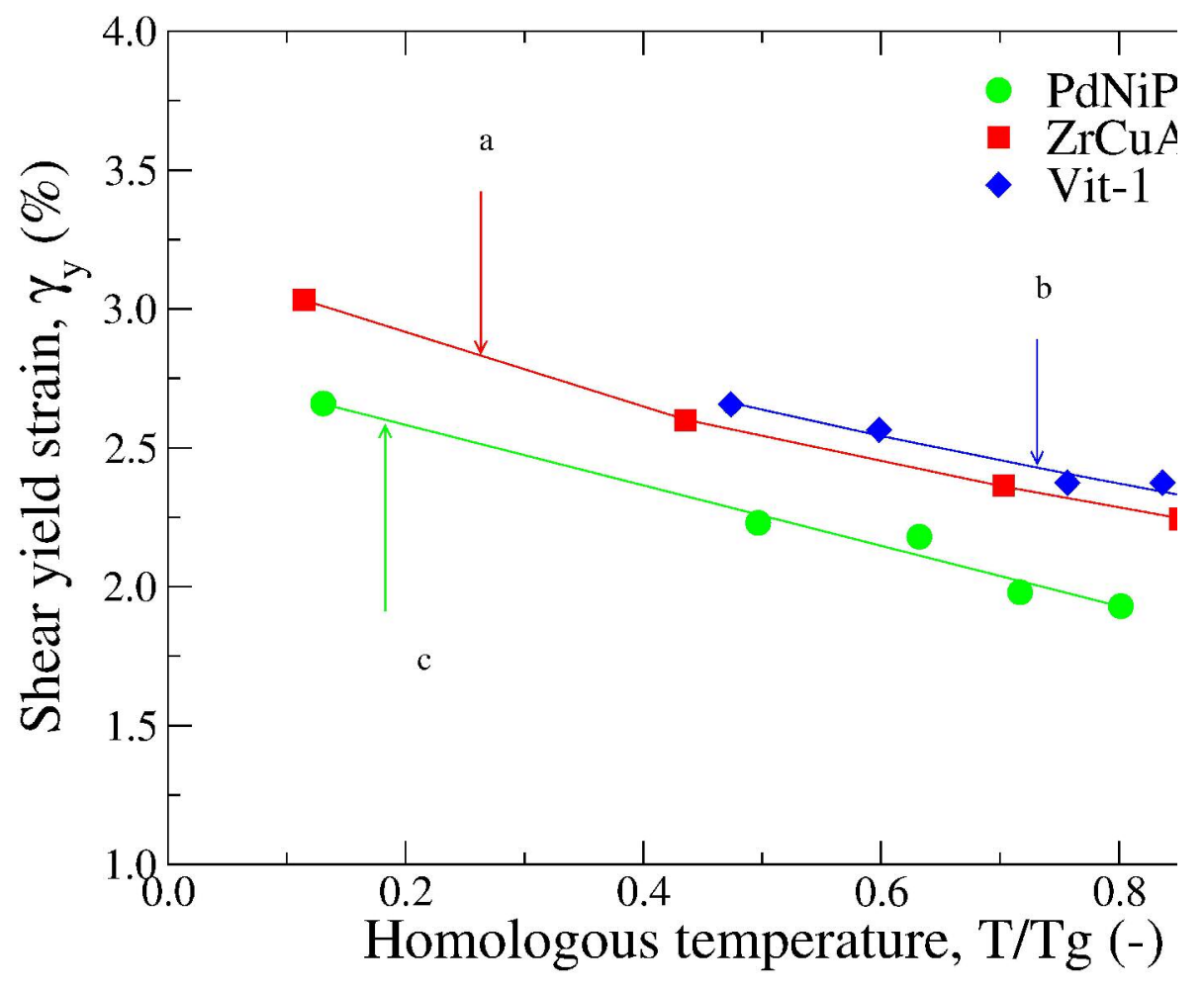

$215 \times 279 m m(600 \times 600$ DPI $)$ 